\title{
Identification of an Acinetobacter baumannii Zinc Acquisition System that Facilitates Resistance to Calprotectin-mediated Zinc Sequestration
}

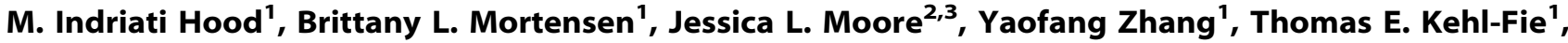 \\ Norie Sugitani ${ }^{3,4}$, Walter J. Chazin ${ }^{3,4,5}$, Richard M. Caprioli ${ }^{2,5}$, Eric P. Skaar ${ }^{1 *}$
}

1 Department of Pathology, Microbiology and Immunology, Vanderbilt University, Nashville, Tennessee, United States of America, 2 Mass Spectrometry Research Center, Vanderbilt University, Nashville, Tennessee, United States of America, 3 Department of Chemistry, Vanderbilt University, Nashville, Tennessee, United States of America, $\mathbf{4}$ Center for Structural Biology, Vanderbilt University, Nashville, Tennessee, United States of America, $\mathbf{5}$ Department of Biochemistry, Vanderbilt University, Nashville, Tennessee, United States of America

\begin{abstract}
Acinetobacter baumannii is an important nosocomial pathogen that accounts for up to 20 percent of infections in intensive care units worldwide. Furthermore, A. baumannii strains have emerged that are resistant to all available antimicrobials. These facts highlight the dire need for new therapeutic strategies to combat this growing public health threat. Given the critical role for transition metals at the pathogen-host interface, interrogating the role for these metals in $A$. baumannii physiology and pathogenesis could elucidate novel therapeutic strategies. Toward this end, the role for calprotectin- (CP)mediated chelation of manganese $(\mathrm{Mn})$ and zinc $(\mathrm{Zn})$ in defense against $A$. baumannii was investigated. These experiments revealed that CP inhibits $A$. baumannii growth in vitro through chelation of $\mathrm{Mn}$ and $\mathrm{Zn}$. Consistent with these in vitro data, Imaging Mass Spectrometry revealed that CP accompanies neutrophil recruitment to the lung and accumulates at foci of infection in a murine model of $A$. baumannii pneumonia. CP contributes to host survival and control of bacterial replication in the lung and limits dissemination to secondary sites. Using CP as a probe identified an $A$. baumannii $\mathrm{Zn}$ acquisition system that contributes to $\mathrm{Zn}$ uptake, enabling this organism to resist CP-mediated metal chelation, which enhances pathogenesis. Moreover, evidence is provided that $\mathrm{Zn}$ uptake across the outer membrane is an energy-dependent process in $A$. baumannii. Finally, it is shown that $Z n$ limitation reverses carbapenem resistance in multidrug resistant $A$. baumannii underscoring the clinical relevance of these findings. Taken together, these data establish $\mathrm{Zn}$ acquisition systems as viable therapeutic targets to combat multidrug resistant $A$. baumannii infections.
\end{abstract}

Citation: Hood MI, Mortensen BL, Moore JL, Zhang Y, Kehl-Fie TE, et al. (2012) Identification of an Acinetobacter baumannii Zinc Acquisition System that Facilitates Resistance to Calprotectin-mediated Zinc Sequestration. PLoS Pathog 8(12): e1003068. doi:10.1371/journal.ppat.1003068

Editor: Ralph R. Isberg, Tufts University School of Medicine, United States of America

Received July 8, 2012; Accepted October 18, 2012; Published December 6, 2012

Copyright: (c) 2012 Hood et al. This is an open-access article distributed under the terms of the Creative Commons Attribution License, which permits unrestricted use, distribution, and reproduction in any medium, provided the original author and source are credited.

Funding: This work was supported by R56AI091771 from the National Institutes of Health to E.P.S. E.P.S. is a Burroughs Wellcome Fund Investigator in the pathogenesis of infectious diseases. M.I.H. was supported by an International Student Research Fellowship through Howard Hughes Medical Institute and by Public Health Service award T32 GM07347 from the National Institute of General Medical Studies for the Vanderbilt Medical-Scientist Training Program. T.E.K. was supported by a post-doctoral fellowship from the American Heart Association. J.L.M was supported by Vanderbilt Chemical Biology Interface training program (T32GM008320). R.M.C. acknowledges the support of NIH/NIGMS 8P41GMI03391-2 (formerly NIH/NCRR 1P41RR031461-01). The funders had no role in study design, data collection and analysis, decision to publish, or preparation of the manuscript.

Competing Interests: The authors have declared that no competing interests exist.

* E-mail: eric.skaar@vanderbilt.edu

\section{Introduction}

Acinetobacter baumannii is an opportunistic pathogen of growing importance in the hospital setting. Responsible for up to 20 percent of infections in intensive care units worldwide, $A$. baumannii is particularly problematic due to its propensity to acquire antibiotic resistance determinants [1-6]. Moreover, the resistance of A. baumannii to common disinfectants and ability to survive for long periods on dry surfaces make it difficult to eradicate from the hospital environment [7-10]. Current multidrug resistance rates range from $48-85 \%$ of isolates, with the greatest burden in Asia and Eastern Europe [1-5]. Pan resistance is likewise emerging, suggesting that more clinicians will soon be faced with infections for which no effective antimicrobial therapies remain [11-15]. Clearly, it is imperative to develop new antimicrobial strategies to combat this emerging threat.
Despite the growing clinical burden of A. baumannii disease there remains relatively little known about the mechanisms of $A$. baumannii pathogenesis or about this organism's physiologic requirements during infection [16]. However, it is established that all bacteria require certain transition metals in order to carry out basic physiologic functions [17]. Moreover, mammalian hosts take advantage of this requirement by limiting the availability of metals in a process referred to as nutritional immunity [17-19]. Although nutritional immunity was first used to describe the withholding of iron from invading bacteria, more recently it has been established that mammalian hosts also sequester manganese $(\mathrm{Mn})$ and zinc (Zn) [17,20-24]. As a result, bacterial pathogens need efficient mechanisms to acquire these metals from their hosts in order to cause disease. The contribution of host-mediated $\mathrm{Mn}$ and $\mathrm{Zn}$ limitation to defense against pulmonary infection has not been elucidated, and the bacterial processes that combat this host 


\section{Author Summary}

Acinetobacter baumannii is a bacterium responsible for an increasing number of infections in the hospital setting. These infections are particularly challenging because most strains of $A$. baumannii are resistant to commonly used antibiotics. Unfortunately, there is relatively little known about this organism and how it causes disease, making it difficult to identify new drug targets. In order to address this problem we examined the role for nutrient manganese $(\mathrm{Mn})$ and zinc $(\mathrm{Zn})$ in $A$. baumannii infections. We have determined that the host protein, calprotectin (CP), contributes to defense against $A$. baumannii pneumonia through chelation of nutrient $\mathrm{Mn}$ and $\mathrm{Zn}$. Moreover, employing purified calprotectin as a probe allowed us to identify a $\mathrm{Zn}$ acquisition system in $A$. baumannii that is required for efficient $\mathrm{Zn}$ uptake in vitro and full pathogenesis in vivo. Finally, we demonstrate that inhibiting $\mathrm{Zn}$ acquisition can reverse antibiotic resistance mechanisms that rely on $\mathrm{Zn}$-dependent enzymes. Taken together, these results demonstrate the importance of $\mathrm{Zn}$ acquisition to $A$. baumannii pathogenesis and antibiotic resistance, establishing $\mathrm{Zn}$ acquisition as a potential target for therapeutic development.

defense in the lung have not been described. In the case of $A$. baumannii, mechanisms for iron acquisition through siderophore biosynthesis and transport machinery have been identified [2530]; however the mechanisms for acquiring other metals, such as $\mathrm{Mn}$ and $\mathrm{Zn}$, remain to be uncovered.

Calprotectin (calgranulin A/B, MRP 8/14) (CP) is a member of the S100 class of EF-hand proteins consisting of a heterodimer of S100A8 and S100A9. CP is an important inflammatory marker and exhibits antimicrobial activity through the chelation of $\mathrm{Mn}$ and Zn [21,31-33]. As a result, CP has been implicated in defense against a variety of bacterial and fungal pathogens [20-24]. CP comprises up to $50 \%$ of the neutrophil cytoplasmic protein content; therefore CP accumulates at sites of infection [34]. Neutrophils are a critical component of the innate response to $A$. baumannii infection suggesting that CP may play a role in defense against A. baumannii in vivo $[35,36]$. Herein, we demonstrate that $\mathrm{CP}$ is abundantly expressed in the murine lung following infectious challenge and that this protein is involved in protection against $A$. baumannii pneumonia and dissemination to other organs. Using CP as a probe uncovered a number of genes required for resistance to $\mathrm{Mn}$ and $\mathrm{Zn}$ limitation and enabled the discovery of a $\mathrm{Zn}$ acquisition system in $A$. baumannii. This system is expressed in low $\mathrm{Zn}$ environments, required for $\mathrm{Zn}$ acquisition, and important for colonization of the lung. Finally, we show that an inability to acquire $\mathrm{Zn}$ reduces $\mathrm{Zn}$-dependent antibiotic resistance mechanisms, increasing the sensitivity of $A$. baumannii to clinically relevant antimicrobials.

\section{Results}

CP contributes to defense against $A$. baumannii infection As a first step toward evaluating the role for CP during $A$. baumannii infection, growth inhibition assays were performed with increasing concentrations of CP in growth media as described in the Materials and Methods (Figure 1a). In these conditions, CP inhibits $A$. baumannii growth with an $\mathrm{IC}_{50}$ of approximately $60 \mu \mathrm{g} /$ $\mathrm{ml}$. Importantly, the inhibitory effect of CP is completely reversed by the addition of excess $\mathrm{Mn}$ and $\mathrm{Zn}$. Moreover, a variant of $\mathrm{CP}$ in which the $\mathrm{Mn}$ and $\mathrm{Zn}$ binding sites are mutated is unable to inhibit A. baumannii growth (Figure S1) [22]. Finally, CP exposure reduces intracellular accumulation of $\mathrm{Mn}$ and $\mathrm{Zn}$, but not $\mathrm{Fe}$, consistent with a role for $\mathrm{CP}$ in sequestering $\mathrm{Mn}$ and $\mathrm{Zn}$ away from A. baumannii (Figure 1b). Taken together, these results establish that CP inhibits $A$. baumannii growth through chelation of $\mathrm{Mn}$ and $\mathrm{Zn}$.

In order to define the contribution of CP to defense against $A$. baumannii pneumonia, we first determined whether $\mathrm{CP}$ is present in lungs of mice infected with $A$. baumannii. CP expression was measured using matrix-assisted laser desorption/ionization Imaging Mass Spectrometry (MALDI IMS). In situ visualization of CP by MALDI IMS has been previously characterized by our laboratory where CP is identified by the signal at $\mathrm{m} / \mathrm{z} 10,165$ corresponding to S100A8 [20,37]. These experiments revealed that CP is not detectable by MALDI IMS in the lungs of uninfected wildtype C57BL/ 6 mice. In contrast, a robust signal for $\mathrm{m} / \mathrm{z} 10,165$ is observed in the lungs of wildtype mice infected with A. baumannii, demonstrating that CP is abundantly expressed in the lungs at 36 hours post infection (hpi) (Figure 2a). S100A9 ${ }^{-1-}$ mice, which are functionally CP-deficient, do not exhibit a signal at $m / z 10,165$, establishing the specificity of these analyses (Figure 2a) [38]. To confirm that the failure to detect calprotectin
A

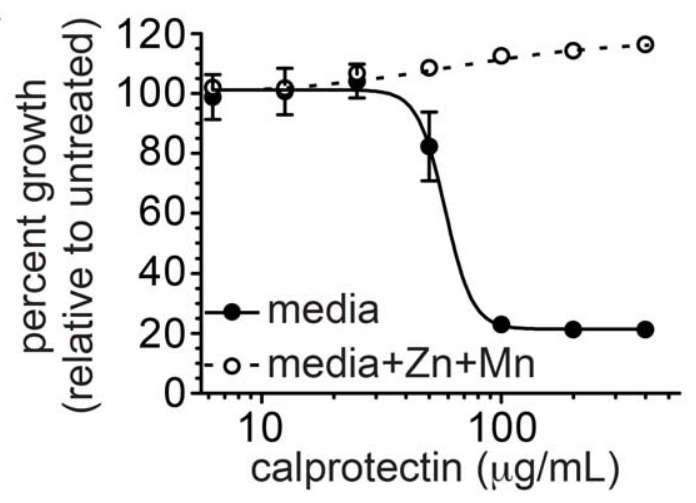

B

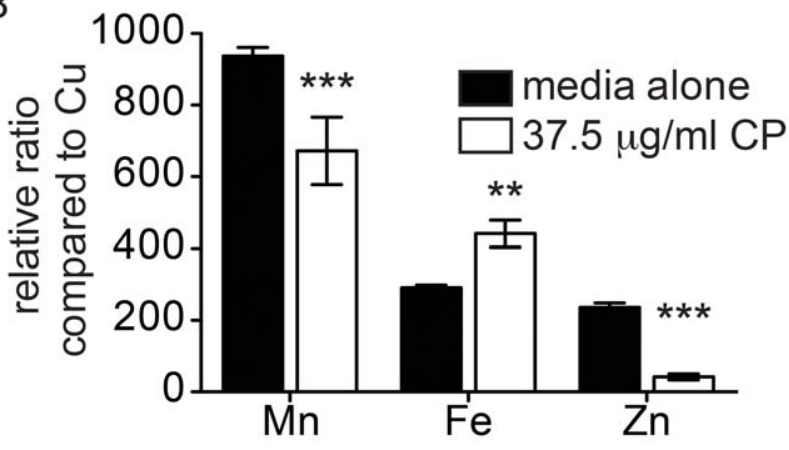

Figure 1. CP inhibits $A$. baumannii growth in vitro through chelation of $\mathrm{Mn}$ and $\mathrm{Zn}$. (A) A. baumannii growth in the presence of increasing concentrations of CP with (dashed lines) or without (solid lines) $25 \mu \mathrm{M} \mathrm{Mn}$ and $25 \mu \mathrm{M} \mathrm{Zn}$ added back. Data represent the average of three biological replicates. (B) Treatment with CP reduces intracellular $\mathrm{Mn}$ and $\mathrm{Zn}$ accumulation. ICP-MS analyses of intracellular $\mathrm{Mn}, \mathrm{Fe}$ and $\mathrm{Zn}$ expressed as the relative ratio compared to intracellular $\mathrm{Cu} .{ }^{* *} p<0.01,{ }^{* * *} p<0.001$ by two-way ANOVA.

doi:10.1371/journal.ppat.1003068.g001 

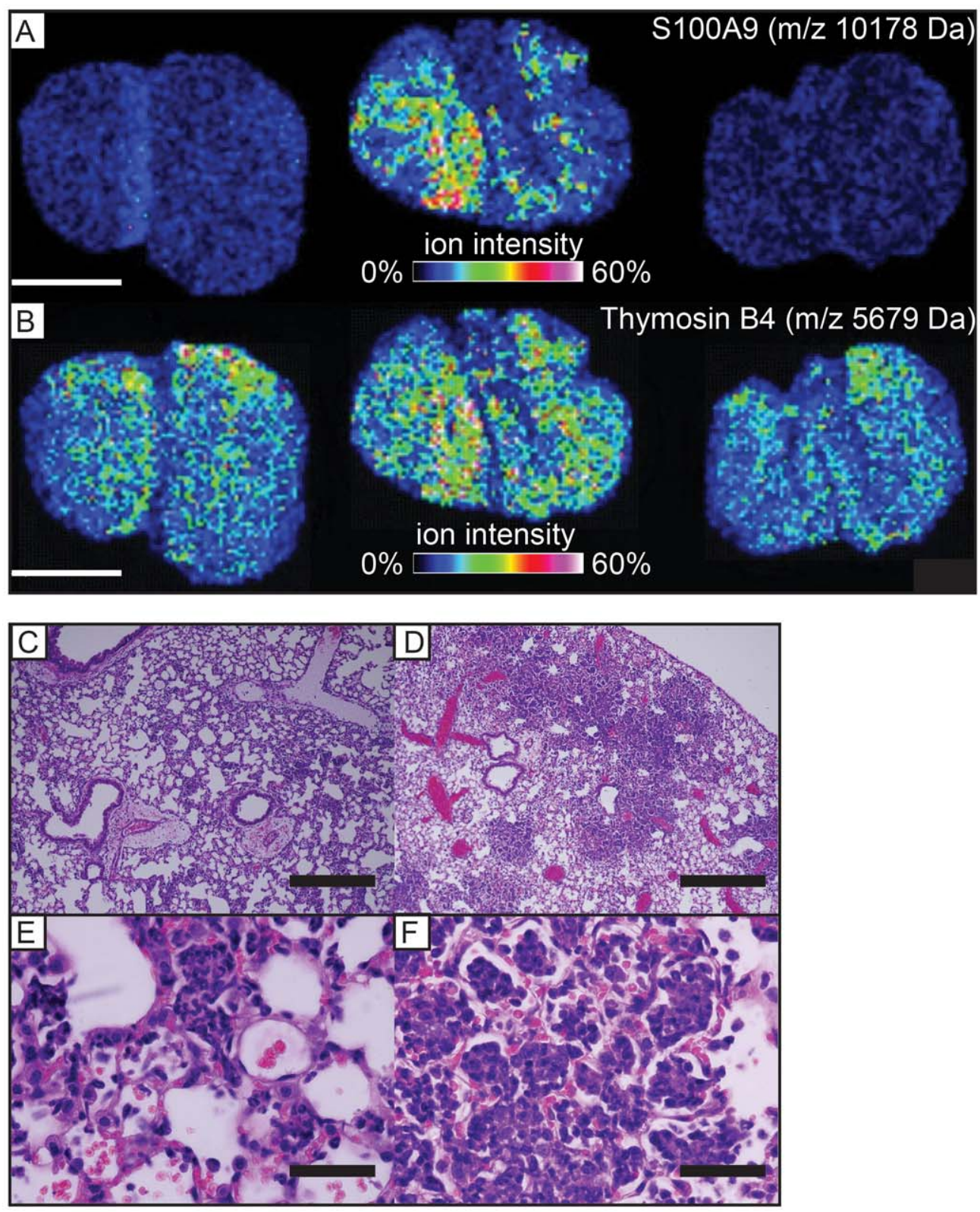

G

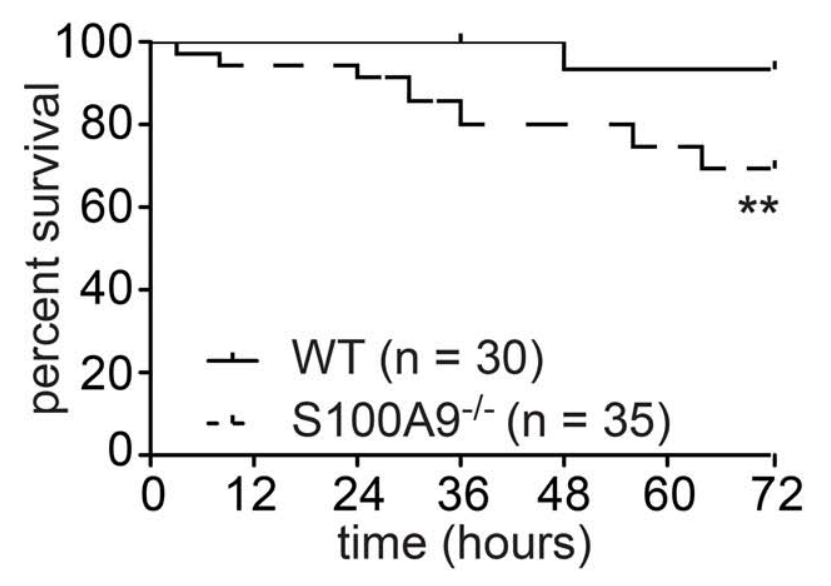

$\mathrm{H}$

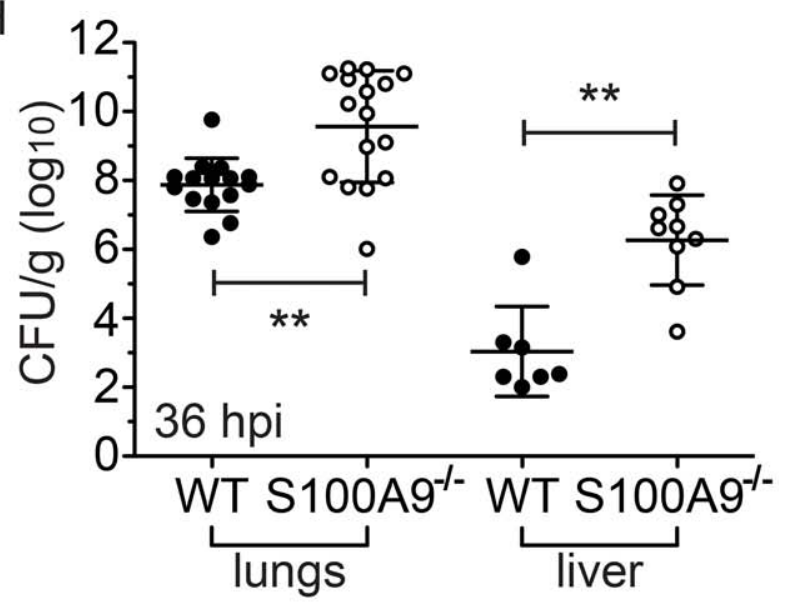

Figure 2. CP contributes to protection against $\boldsymbol{A}$. baumannii infection. (A-B) IMS detection of host proteins in lungs harvested at 36 hpi with A. baumannii. Scale bar $=2 \mathrm{~cm}$. (A) Heat map demonstrating the distribution and abundance of $\mathrm{S} 100 \mathrm{~A} 8(\mathrm{~m} / \mathrm{z}=10,165.8 \pm 5 \mathrm{Da})$ in uninfected wildtype (left) and infected wildtype (middle) or S100 $\mathrm{A}^{-1-}$ (right) mice. (B) Heat map demonstrating the distribution and abundance of a protein exhibiting 
$\mathrm{m} / \mathrm{z} 5,679 \pm 5 \mathrm{Da}$ in uninfected wildtype (left) and infected wildtype (middle) or S100A9 ${ }^{-/-}$(right) mice. (C-F) Hematoxylin and eosin stained histological sections taken from lungs harvested at $36 \mathrm{hpi}$ from mice infected with $A$. baumannii. (C, E) Wildtype C57BL/6. (D, F) S100A ${ }^{-1-}$. Scale bars equal $500 \mu \mathrm{m}(\mathrm{C}-\mathrm{D})$ and $50 \mu \mathrm{m}(\mathrm{E}-\mathrm{F})$. Images are representative of sections taken from three mice for each genotype. (G) Survival of wildtype or $\mathrm{CP}$-deficient mice following infection with A. baumannii. Data were combined from three independent experiments with 8-16 mice per group in each experiment. ${ }^{*} p<0.01$ as determined by Gehan-Breslow-Wilcoxon Test. $(\mathbf{H})$ Bacterial burden in lungs and livers of wildtype or CP-deficient mice $36 \mathrm{hpi}$ with $A$. baumannii. Data were averaged from three independent experiments with $5-10$ mice per group in each experiment. ${ }^{* *} p<0.01$ as determined by Student's $t$ test.

doi:10.1371/journal.ppat.1003068.g002

in $\mathrm{S} 100 \mathrm{~A} 9^{-/-}$mice is not due to insufficient tissue or a generalized diminished protein signal in these sections we analyzed the signal at $m / z 5,679$ whose abundance is not affected by infection (Figure 2b) [39]. This signal did not differ between wildtype and S100A9 ${ }^{-/-}$mice demonstrating the biological relevance of the differential signal at $m / z 10,165$. Histological analyses of lung sections demonstrated robust inflammatory cell recruitment to the infected lungs in both wildtype and S100A9 ${ }^{-/-}$ mice (Figure 2c-f). However, in S100A $9^{-/-}$lungs, the infectious and inflammatory foci involve more of the total lung area and more alveoli are packed with neutrophils as compared to wildtype mice. Taken together, these data demonstrate that CP accumulation in the lungs of wildtype mice coincides with neutrophil accumulation at sites of infection.

To determine the contribution of $\mathrm{CP}$ to protection against bacterial pneumonia, the susceptibility of S100A9 ${ }^{-/-}$mice to $A$. baumannii infection was compared to that of wildtype C57BL/6 mice. Although A. baumannii rarely causes lethal infection in immunocompetent mice, S100A $9^{-\prime-}$ mice exhibit a significant increase in mortality over a 72-hour time course (Figure 2g). Consistent with this observation, bacterial burdens are significantly higher at 36 hpi in the lungs of S100A $9^{-/-}$mice compared to wildtype (Figure 2h). Moreover, dissemination to secondary sites is also increased in CP-deficient mice as evidenced by an increase in bacterial burden in livers. A significant increase in bacterial burden was not observed at 72 hpi in S100A9 ${ }^{-/-}$mice suggesting that mice that survive to 72 hours are eventually able to control infection (Figure S2). These data implicate CP as an important component of the innate immune response to $A$. baumannii pulmonary infections.

\section{Identification of $A$. baumannii mutants with altered sensitivity to $\mathrm{CP}$}

The contribution of CP to defense against A. baumannii infection suggests that $A$. baumannii requires $\mathrm{Mn}$ and/or $\mathrm{Zn}$ in order to maximally colonize the murine lung. Moreover, CP can serve as a valuable reagent to interrogate the contribution of $\mathrm{Mn}$ and $\mathrm{Zn}$ acquisition to $A$. baumannï physiology and pathogenesis. In order to determine the impact of $\mathrm{Mn}$ and $\mathrm{Zn}$ limitation on $A$. baumannii physiological processes, a transposon library was screened to identify mutants with either increased or decreased resistance to CP (Figure 3a). Approximately 4000 mutants were screened and 40 were selected whose growth was significantly different from wildtype in the presence of CP, but unchanged compared to wildtype in the absence of CP. Interestingly, a majority of the mutants cluster into a few common functional categories based on the annotations of the proteins encoded by the disrupted genes (Figure 3b and Table 1). These categories include biofilm formation and polysaccharide production, inorganic ion transport, and DNA replication or repair suggesting that these processes are involved in defense against CP.

\section{Identification of a $\mathrm{Zn}$ uptake system in A. baumannii}

In one mutant, 4G7, the transposon disrupts A1S_0143, which is annotated as encoding the permease component of a previously unstudied ABC family $\mathrm{Zn}$ transporter. Consistent with a role for A1S_0143 in Zn transport, disruption of this gene by transposon integration leads to increased sensitivity to GP (Figure 3c). A1S_0143 encodes a protein with similarity to ZnuB, a permease involved in $\mathrm{Zn}$ uptake that is found in several other bacteria [4043]. ZnuB is typically part of an ABC-family transporter where $\mathrm{ZnuC}$ is the cognate ATPase and ZnuA is the periplasmic substrate-binding protein [40-43]. A1S_0144 and A1S_0146 encode an ATPase and a periplasmic binding protein similar to ZnuC and ZnuA, respectively (Figure 4a). Based on these observations and data presented below, we designate A1S_0143 as A. baumannii znuB. Notably, the znuABC genes are present in all available sequenced $A$. baumannii genomes (data not shown). To eliminate the potential for polar effects on neighboring genes caused by transposon integration, we generated a targeted deletion mutant in which $z n u B$ was replaced by an in-frame copy of the kanamycin resistance gene, aph $(\Delta z n u B)$. $\Delta z n u B$ was used for all subsequent experiments.

Since CP chelates both $\mathrm{Mn}$ and $\mathrm{Zn}$, we first determined whether $\Delta z n u B$ is more sensitive to $\mathrm{Mn}$ or $\mathrm{Zn}$ chelation by CP. CP growth inhibition assays were repeated with $\Delta z n u B$ in $\mathrm{CP}$ growth medium. CP growth medium was chosen over the transposon screening medium since this medium allows for better titration of the $\mathrm{Zn}$ and $\mathrm{Mn}$ concentrations allowing for differentiation between the effects of $\mathrm{Zn}-$ and Mn-chelation on $\Delta z n u B$. Wildtype and $\Delta z n u B$ exhibited similar growth levels and were not inhibited by $\mathrm{CP}$ when either $\mathrm{Zn}$ alone or $\mathrm{Zn}$ and $\mathrm{Mn}$ are added back to $\mathrm{CP}$ growth media (Figure $4 \mathbf{b}$ and Figure S3). In contrast, when only $\mathrm{Mn}$ was added back to CP growth media, CP significantly inhibited the growth of $\Delta z n u B$. The observation that growth of $\Delta z n u B$ cannot be rescued by supplementation with $\mathrm{Mn}$ alone confirms that this mutant is sensitive to $\mathrm{Zn}$ limitation by CP. It was noted that even in the absence of CP, both wildtype and $\Delta z n u B$ exhibited reduced growth in media alone compared to media supplemented with Mn and Zn (Figure S4). This suggests that the basal $\mathrm{Mn}$ and $\mathrm{Zn}$ levels in the media are insufficient to support growth of wildtype above that of $\Delta z n u B$, regardless of CP exposure. Consistent with this hypothesis, $\Delta z n u B$ exhibited impaired growth compared to wildtype in rich media (LB) in the presence of the Zn-selective chelator, TPEN (Figure 4c). Moreover, the growth defect of the mutant was completely rescued by the addition of excess $\mathrm{Zn}$, further supporting the role for $\mathrm{ZnuB}$ in $\mathrm{Zn}$ acquisition (Figure 4c). Finally, providing a fulllength copy of $z n u B$ in trans rescues the TPEN sensitivity of $\triangle z n u B$, allowing growth at nearly wildtype levels (Figure $\mathbf{4 d}$ ).

\section{Regulation of $z n u B$ in Zn-limiting conditions}

The expression of bacterial high affinity transition metal transporters must be tightly regulated since transition metals can be toxic at high levels. Repression of metal uptake systems under nutrient replete conditions is frequently accomplished through metal-responsive transcriptional regulators like those in the Fur (ferric uptake regulator) family of transcriptional regulators. These regulators bind to target DNA sequences when bound to their cognate metal ligand to repress transcription. To determine 
A

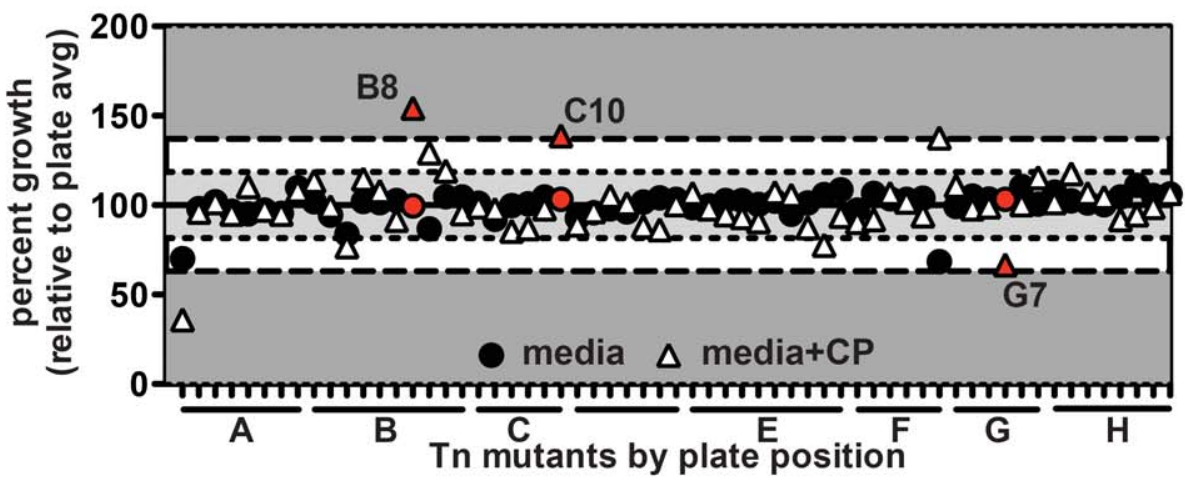

B
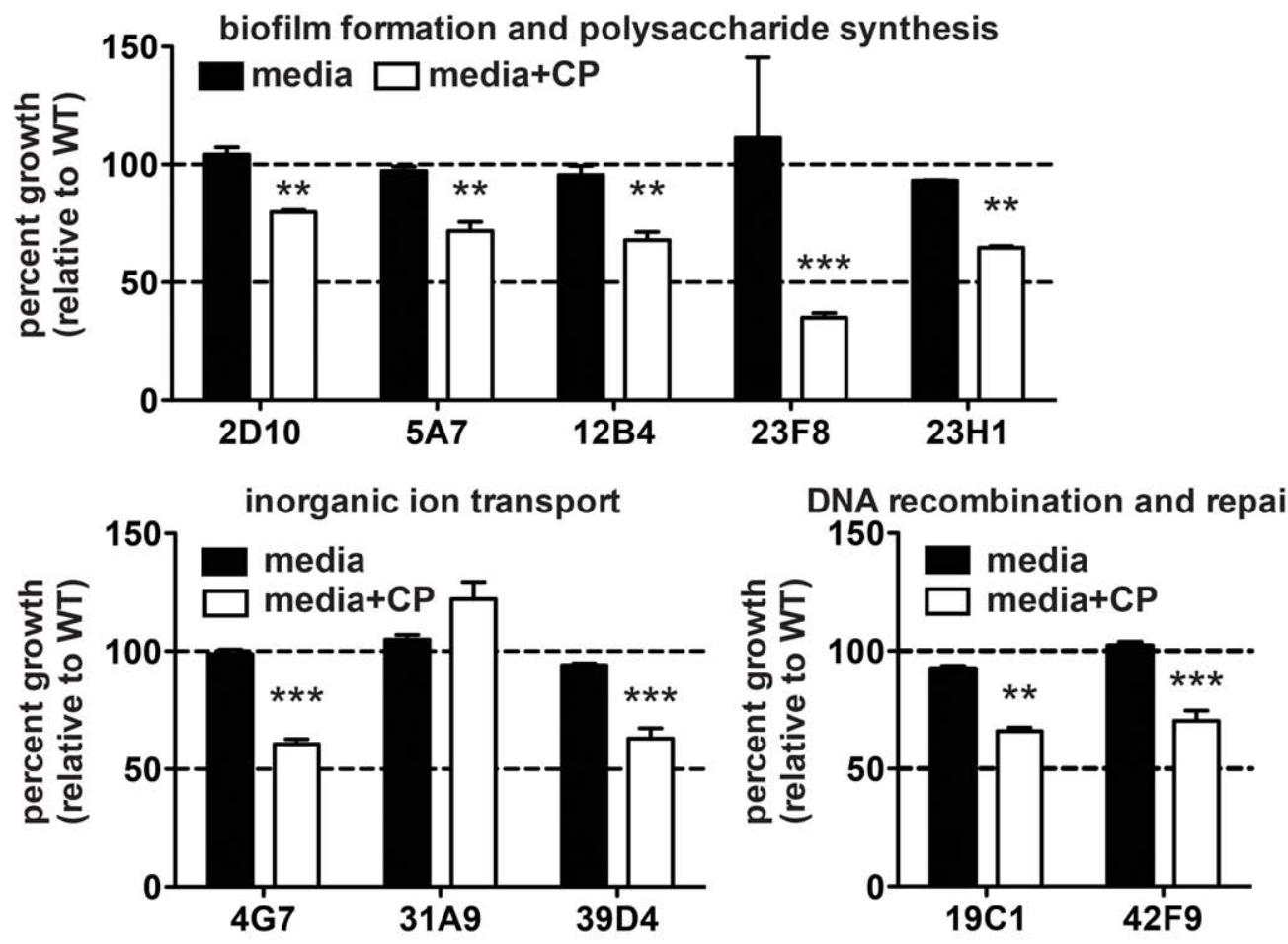

C

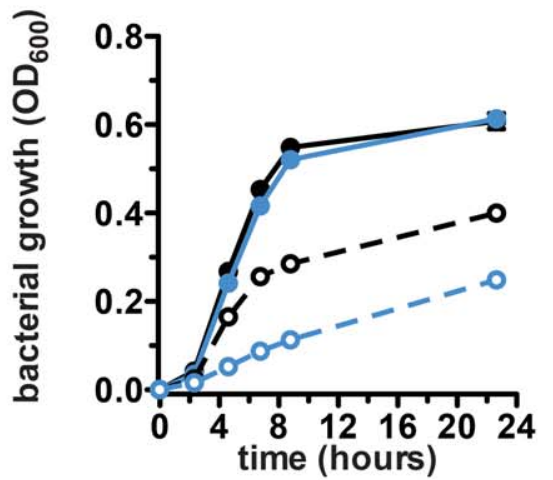

$\rightarrow$ WT

- znuB ::Tn5 (4G7)

$\multimap-\mathrm{WT}+25 \mu \mathrm{g} / \mathrm{mL}$ CP

- - znuB ::Tn5 + 25 $\mu \mathrm{g} / \mathrm{mL}$ CP

WT IC ${ }_{50}=28.33 \mu \mathrm{g} / \mathrm{mL}$

znuB::Tn5 IC ${ }_{50}=21.62 \mu \mathrm{g} / \mathrm{mL}$

Figure 3. Transposon library screen to identify bacterial processes affected by CP treatment. (A) Bacterial growth from a representative plate of mutants cultured in media alone or media with $40 \mu \mathrm{g} / \mathrm{ml} \mathrm{CP}$. Data for wells in which no bacterial growth was observed in either condition have been omitted. Red symbols indicate mutants selected for secondary screening (see Materials and Methods). (B) Growth of selected mutants relative to wildtype bacteria cultured in media alone or media containing $40 \mu \mathrm{g} / \mathrm{ml}$ CP. Mutants are classified according to the predicted functional category of the gene disrupted by the transposon. ${ }^{* *} p<0.01, * * * p<0.001$ for relative growth in the presence of CP compared to media alone, as determined by two-way ANOVA. (C) Growth curves comparing wildtype A. baumannii and znuB::Tn5 in the presence or absence of $25 \mu \mathrm{g} / \mathrm{ml} \mathrm{CP}$. IC $\mathrm{C}_{50}$ values were determined as described in the Materials and Methods.

doi:10.1371/journal.ppat.1003068.g003 
Table 1. Transposon mutants with altered sensitivity to $C P$.

\begin{tabular}{|c|c|c|c|c|}
\hline Mutant ID & Locus tag & Description & Phenotype & Insert type \\
\hline PDL05G12 & A1S_2148 & $\begin{array}{l}\text { flavin reductase-like protein; putative acetyl-CoA } \\
\text { synthetase/AMP-(fatty) acid ligase }\end{array}$ & resistant & intergenic \\
\hline PDL31A10 & A1S_0352 & hypothetical protein & resistant & intergenic \\
\hline PDL02D10 & A1S_2505; A1S_2506 & $\begin{array}{l}\text { hypothetical protein }\left(110 \mathrm{bp} 5^{\prime}\right) \text {; putative GGDEF } \\
\text { family protein }\left(290 \mathrm{bp} 3^{\prime}\right)\end{array}$ & sensitive & intergenic \\
\hline PDL23H1 & A1S_2841; A1S_2842 & $\begin{array}{l}\text { putative type } 4 \text { fimbrial biogenesis protein FimT (not } \\
\text { present in the SEED); Acetyl-CoA C-acyltransferase }\end{array}$ & sensitive & intergenic \\
\hline PDL15F1 & A1S_3277 & putative pirin-like protein & sensitive & intergenic \\
\hline PDL03F9 & A1S_0367 & $\begin{array}{l}\text { glutathione-regulated potassium-efflux system } \\
\text { protein }(K(+) / H(+) \text { antiporter) (KefB) }\end{array}$ & resistant & intragenic \\
\hline PDL03H9 & A1S_0367 & $\begin{array}{l}\text { glutathione-regulated potassium-efflux system } \\
\text { protein }(\mathrm{K}(+) / \mathrm{H}(+) \text { antiporter) }\end{array}$ & resistant & intragenic \\
\hline PDL03H10 & A1S_0367 & $\begin{array}{l}\text { glutathione-regulated potassium-efflux system } \\
\text { protein }(K(+) / H(+) \text { antiporter })\end{array}$ & resistant & intragenic \\
\hline PDL05D12 & A1S_0196 & Long-chain-fatty-acid-CoA ligase & resistant & intragenic \\
\hline PDL06C3 & A1S_3463 & Cro-like protein (pAb1) & resistant & intragenic \\
\hline PDL26D12 & A1S_2040 & putative phage integrase & resistant & intragenic \\
\hline PDL31A11 & A1S_1053 & hypothetical protein & resistant & intragenic \\
\hline PDL31A9 & A1S_0118 & hypothetical protein & resistant & intragenic \\
\hline PDL11C6 & A1S_3142 & putative membrane protein & resistant & intragenic \\
\hline PDL04G7 & A1S_0143 & high affinity $\mathrm{Zn}$ transport protein & sensitive & intragenic \\
\hline PDL06H4 & A1S_2477 & isocitrate dehydrogenase & sensitive & intragenic \\
\hline PDL09F4 & A1S_0076 & aconitate hydratase & sensitive & intragenic \\
\hline PDL05A7 & A1S_0430 & Putative glycosyltransferase & sensitive & intragenic \\
\hline PDL19C1 & A1S_2588 & Holliday junction DNA helicase RuvB & sensitive & intragenic \\
\hline PDL22A12 & A1S_0023 & putative malic acid transport protein & sensitive & intragenic \\
\hline PDL23E2 & A1S_3472 & DNA replication protein (pAB2) & sensitive & intragenic \\
\hline PDL23F8 & A1S_0060 & hypothetical protein & sensitive & intragenic \\
\hline PDL12B4 & A1S_0749 & BfmS & sensitive & intragenic \\
\hline PDL42C3 & A1S_3352; A1S_3353 & $\begin{array}{l}\text { putative } \mathrm{OHCU} \text { decarboxylase; putative } \\
\text { transthyretin-like protein precursor }\end{array}$ & sensitive & intragenic \\
\hline PDL42F9 & A1S_0696 & putative MutT/nudix family protein & sensitive & intragenic \\
\hline PDL39D4 & A1S_0118 & hypothetical protein & sensitive & intragenic \\
\hline
\end{tabular}

doi:10.1371/journal.ppat.1003068.t001

whether $z n u B$ is under similar transcriptional control in $A$. baumannii, we first cloned the promoter for the znu operon upstream of a gene encoding GFP. Both wildtype and $\Delta z n u B$ were then transformed with the plasmid carrying the znu reporter (pznuGFP) and grown in LB with or without the addition of TPEN or Zn. Wildtype bacteria exhibited increased fluorescence upon increasing concentrations of TPEN (Figure 4e). Similarly, $\Delta z n u B$ demonstrated increasing fluorescence with increasing $\mathrm{Zn}$ chelation, although the basal level of GFP expression at all TPEN concentrations was higher in $\triangle z n u B$ as compared to wildtype. Moreover, $\Delta z n u B$ exhibited a greater increase in fluorescence at high concentrations of TPEN. Importantly, with the addition of excess $\mathrm{Zn}$, the fluorescence observed for $\Delta z n u B$ could be restored to levels equivalent to the basal levels observed in wildtype bacteria (Figure 4f). These results establish that the $z n u$ operon is upregulated in $\mathrm{Zn}$-limiting conditions and that $\Delta z n u B$ experiences $\mathrm{Zn}$ starvation at higher $\mathrm{Zn}$ concentrations than wildtype.

A potential mechanistic explanation for the Zn-regulated nature of $z n u$ was provided by the discovery of a putative Zur (Zinc uptake regulator) orthologue neighboring these genes (Figure $\overline{\mathbf{5}} \mathbf{a}$ ).
Based on data described below, we refer to this gene as the $A$. baumannii zur. Zur is a member of the Fur family of transcriptional regulators and in other bacteria Zur mediates Zn-dependent repression of a number of genes including $\mathrm{Zn}$ uptake systems [40,41,44-48]. To determine if the A. baumannii Zur binds Zn, we performed a 4-(2-pyridylazo)-resorcinol (PAR) assay to measure Zur-mediated $\mathrm{Zn}$ binding. This assay is based on the principle that PAR exhibits a peak absorbance at approximately $410 \mathrm{~nm}$ in its free form, while this peak shifts to $495 \mathrm{~nm}$ upon $\mathrm{Zn}$ binding. Addition of a $\mathrm{Zn}$ binding protein to PAR-Zn leads to a reduction in the peak at $495 \mathrm{~nm}$ and an increase in the peak at $410 \mathrm{~nm}$. When increasing concentrations of purified Zur were added to PAR-Zn, the Zn-bound peak at $495 \mathrm{~nm}$ decreased while the peak at $410 \mathrm{~nm}$ increased, establishing that $A$. baumannii Zur binds to $\mathrm{Zn}$ in vitro (Figure 5b).

Zur is a $\mathrm{Zn}$-dependent repressor that binds to a $19 \mathrm{bp}$ consensus sequence in the presence of $\mathrm{Zn}$ to repress transcription of a number of genes including those involved in Zn uptake [45-49]. The intragenic region between znuA and zur was searched for a possible Zur-binding site using the consensus sequence from $\gamma$ - 
A

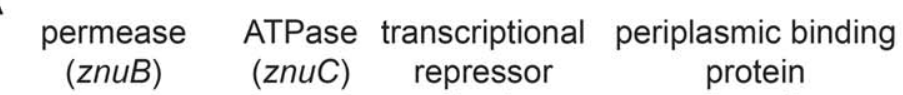

A1S_0143 A1S_0144 A1S_0145 (zur)

B

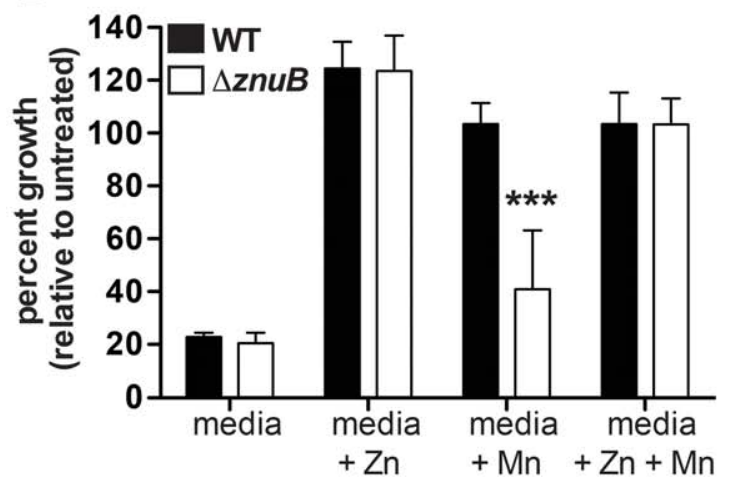

E

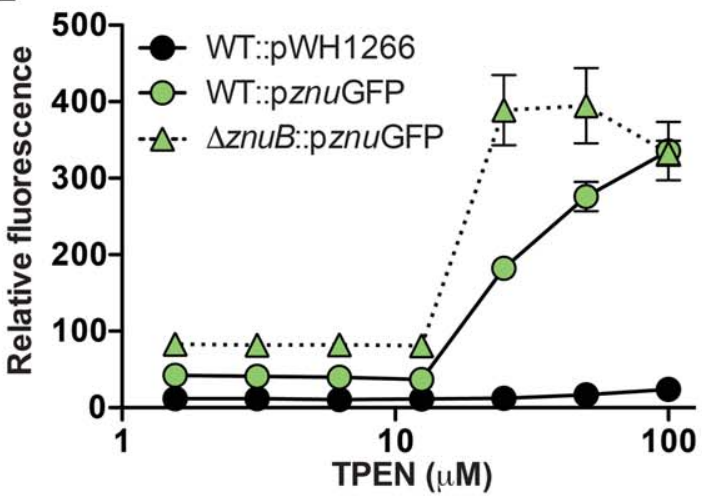

C

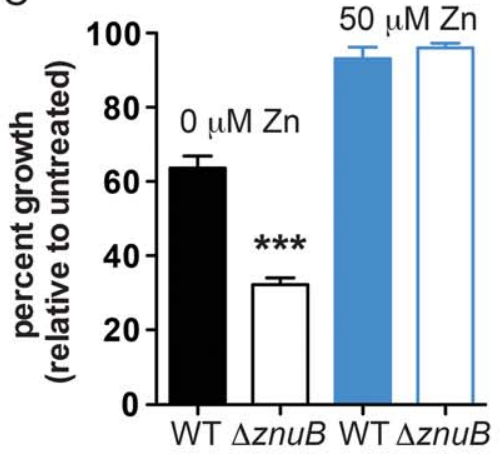

D

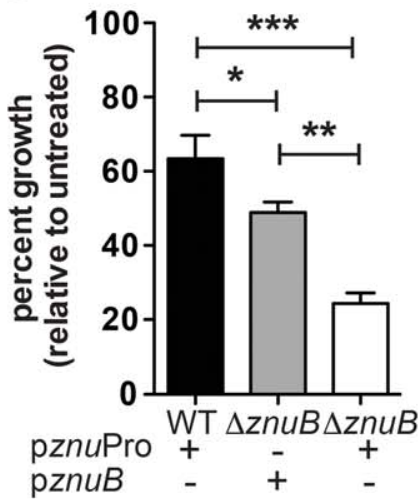

$\mathrm{F}$

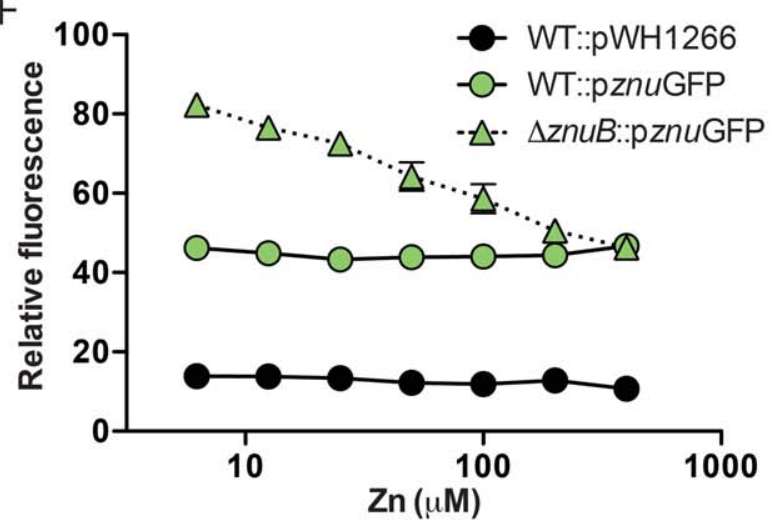

Figure 4. Contribution of $z n u B$ to growth in Zn-limiting conditions. (A) Schematic representation of the genomic context adjacent to A1S_0143. (B) CP growth inhibition assays comparing wildtype with $\triangle$ znuB. Bacteria were cultured in CP growth media in the presence of increasing concentrations of CP with or without addition of $25 \mu \mathrm{M} \mathrm{Zn,} 25 \mu \mathrm{M} \mathrm{Mn}$ or both $25 \mu \mathrm{M} \mathrm{Zn}$ and $25 \mu \mathrm{M}$ Mn. Data for $100 \mu \mathrm{g} / \mathrm{ml} \mathrm{CP}$ are presented as the percent growth relative to bacterial growth without CP. Data are the average of three independent experiments with at least three biological replicates each. (C) Comparison of the effect of $25 \mu \mathrm{M}$ TPEN on inhibition of wildtype and $\Delta z n u B$ with or without addition of excess (50 $\mu \mathrm{M}$ ) $\mathrm{Zn}$. (D) Complementation of the sensitivity of $\triangle z n u B$ to $20 \mu \mathrm{M}$ TPEN by providing a wildtype copy of $z n u B$ in trans. Data are representative of three independent experiments with at least three biological replicates in each. ${ }^{*} p<0.05,{ }^{* *} p<0.01,{ }^{* * *} p<0.001$ as determined by one-way ANOVA. (E-F) Assessment of znu promoter activity in the presence of increasing concentrations of TPEN (E) or Zn (F) using a GFP reporter. GFP activity is expressed as relative fluorescence where the intensity of the signal is normalized to the optical density of the culture.

doi:10.1371/journal.ppat.1003068.g004

Proteobacteria [48]. This search yielded a possible Zur-binding sequence within $100 \mathrm{bp}$ of the $z n u A$ translational start site (Figure 5a). Since a second candidate Zur binding site was not identified in the region between znuA and zur, it is likely that binding at this sequence leads to repression of both znuA and zurznuCB. To determine if Zur binds to this putative Zur box in a Zn-dependent manner, electrophoretic mobility shift assays were performed using purified Zur and oligonucleotides corresponding to the sequences shown in Figure 5a. When Zur is mixed with target DNA in the presence of excess Zn, the target DNA exhibits a shift in molecular weight consistent with Zur binding (Figure 5c). This shift is not observed when DNA corresponding to an intragenic region of $z n u A$ is used (Figure 5d). Moreover, addition of EDTA eliminated Zur binding to the target DNA, demonstrating that DNA binding is Zn-dependent (Figure 5e). Taken together, these data demonstrate that Zur is a Zn-binding protein that binds to the promoter of $z n u A$ and zurznuCB in a $\mathrm{Zn}-$ dependent manner.

Using the putative $A$. baumannii zur box sequence, we next conducted a BLAST search against the A. baumannii genome in order to identify additional candidate Zur-regulated genes (Figure 5f and Table 2). These putative Zur-regulated genes were further validated by searching for sequence motifs within their $5^{\prime}$ flanking sequences. The latter analysis, which employed the MEME analysis tool, independently identified the Zur box in a majority of the genes analyzed. Based on these results a list of putative Zur-regulated genes was constructed (Table 2). A number of the predicted Zur-regulated genes in A. baumannii are 
A

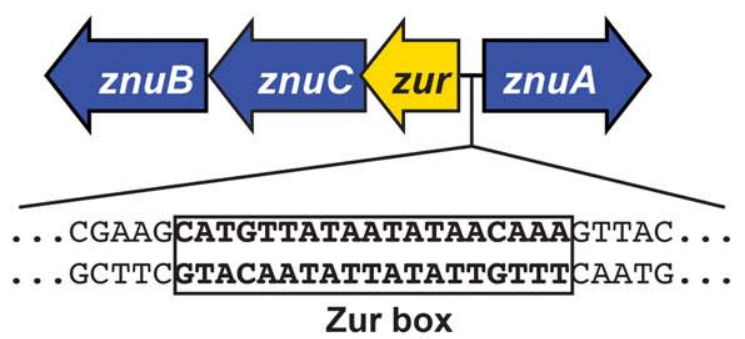

B

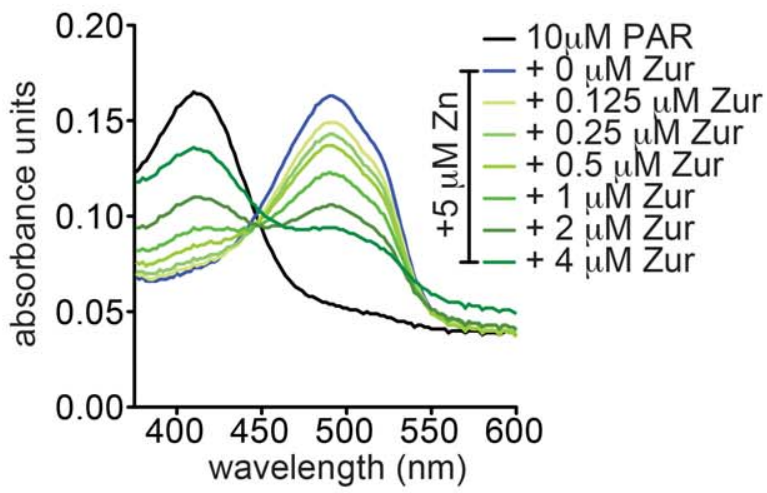

C Zur target sequence

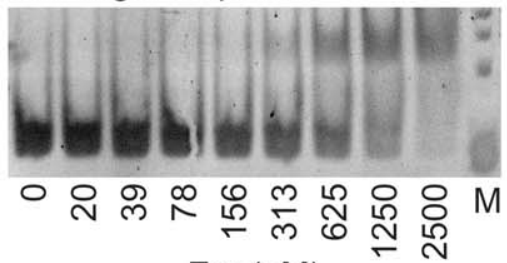

Zur (nM)
D negative control DNA

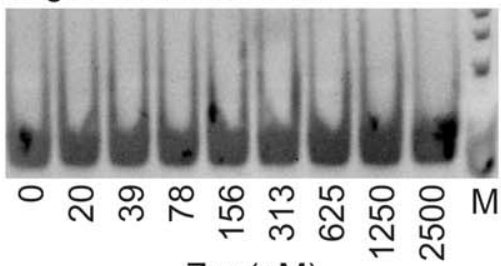

Zur (nM)
E EDTA

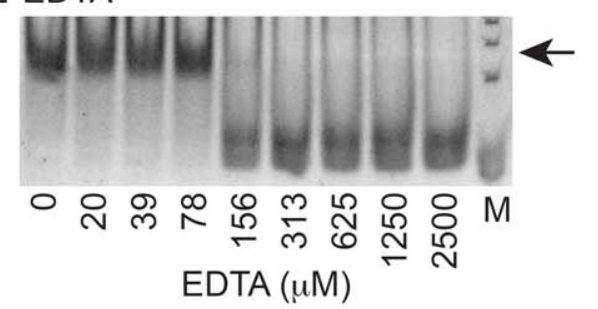

$\mathrm{F}$

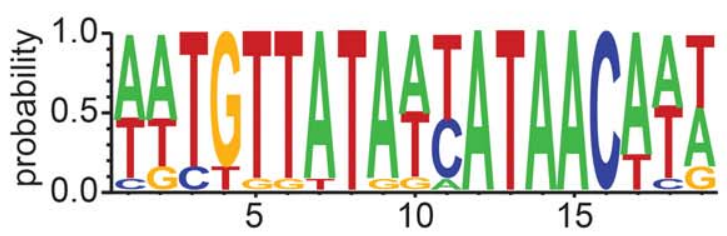

G

AATGTTATAWTATAACATT

AATGTTATAATATAACATT

CATGTTATAATATAACAAA

TTTGTTATATTATAACATG TATGTTATAATATAACATT ATTGTTATAATATAACATT TATGTTATAACATAACATT TTTGTTATAAAATAACAAA AGTGTTATGTTATAACATT AATGTTATAACATAACTAG AACGTTATAGCATAACTCA AGTGTTATAATATAACATA TACTGTATAACATAACAAT TTTTTGTTATСATAАСTAT

\author{
$\gamma$-Proteobacteria consensus \\ A. baumannii consensus \\ Zur/ZnuCB \\ ZnuA \\ Putative TonB-dependent receptor (ZnuD1, chr) \\ Hypothetical protein, putative signal peptide \\ Putative metal-dependent chaperone, G3E family GTPase \\ Uncharacterized ABC transporter (LPS assembly) \\ Ribosomal protein L31 \\ TonB1/ExbB1/ExbD1 \\ Carbonic anhydrase \\ Putative TonB-dependent receptor (ZnuD2, pAB2) \\ LysR family transcriptional regulator \\ Putative TonB-dependent receptor
}

$\mathrm{H}$

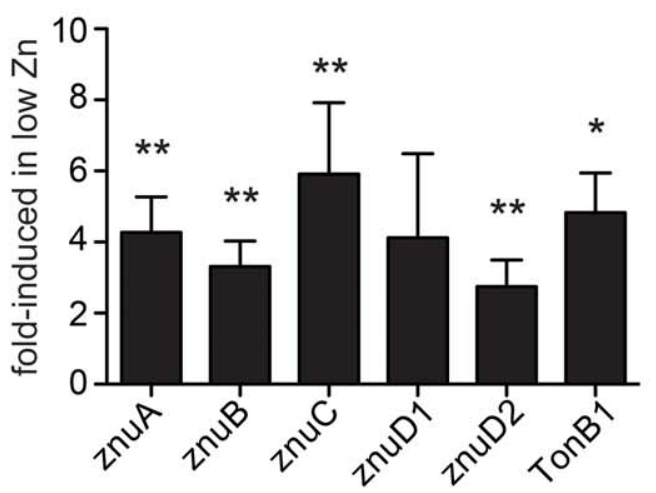


Figure 5. Genetic characterization of a putative $\mathrm{Zn}$ uptake system in $\boldsymbol{A}$. baumannii. (A) Schematic representation of the genomic locus containing znuA and the zurznuCB operon. The sequence corresponding to a putative zur box is shown. (B) PAR assay measuring Zn binding by Zur. Spectral scans of solutions containing $10 \mu \mathrm{M}$ PAR without Zn (black line), with Zn (blue line) or with Zn and increasing concentrations of Zur (green lines) are shown. (C-D) EMSA assays measuring binding of Zur to Zur target DNA (C) or negative control DNA (D) in the presence of Zn. (E) EMSA assay demonstrating loss of Zur binding to target DNA in the presence of increasing concentrations of EDTA. Arrow indicates mobility of shifted band. (F) Consensus sequence for the A. baumannii Zur box. (G) Predicted Zur-regulated genes and their predicted Zur boxes. (H) Expression analyses of genes predicted to be involved in $\mathrm{Zn}$ uptake across the outer (znuD1, znuD2, TonB1) and inner (znuA, znuB, znuC) membranes. Asterisks indicate relative expression that is statistically greater than one, where 1-fold indicates no change in expression in TPEN treated bacteria compared to untreated bacteria. ${ }^{*} p<0.05,{ }^{*} p<0.01$ as determined by one sample $t$ test using a reference value of one.

doi:10.1371/journal.ppat.1003068.g005

regulated by Zur in other bacteria. These include the ribosomal L31 protein, a carbonic anhydrase and the Znu system $[44,47,48,50]$ (Figure 5g). While the functional significance of Zur regulation has been elucidated for some of these genes, in many cases the function of the encoded proteins and their roles in $\mathrm{Zn}$ homeostasis have not been defined. Interestingly, A. baumannii Ab17978 encodes two predicted TonB-dependent receptors with highly conserved Zur-binding sequences located within their predicted promoters. One of these genes, A1S_2892 is encoded within the chromosome, while A1S_3475 is encoded within one of this strain's native plasmids. Respectively, these transporters are 41-42 percent identical and 58-61 percent similar, to ZnuD, a Zur-regulated receptor involved in $\mathrm{Zn}$ and heme transport in $\mathcal{N}$. meningitidis [51]. Based on this sequence conservation and putative Zur-regulation, we have designated these genes as $A$. baumannii znuD1 (A1S_2892) and znuD2 (A1S_3475). A third TonBdependent receptor was also identified; however, the predicted protein does not share significant sequence conservation with ZnuD.

To determine whether these candidate Zur-regulated genes are expressed under Zn-limiting conditions, A. baumannii was grown in LB or LB supplemented with the Zn-chelator, TPEN, at a concentration of $10 \mu \mathrm{M}$. This concentration was selected because at this concentration of TPEN $\Delta z n u B$ begins to exhibit decreased growth compared to wildtype. This suggests that the Znu system is required for optimal growth at $10 \mu \mathrm{M}$ TPEN and is therefore likely to be induced under these conditions in wildtype bacteria. Consistent with this hypothesis, transcripts for $z n u A$, znuB, znuC, znuD1 and znuD2 were all increased in TPEN-containing media compared to media without TPEN (Figure 5h). Up-regulation of znuABC, znuD1, and znuD2 under Zn-limiting conditions supports the hypothesis that these genes are involved in $\mathrm{Zn}$ acquisition.

The outer membrane of Gram-negative bacteria represents a significant permeability barrier for ions and small molecules. In many bacteria, transport of transition metal ions across the outer membrane is thought to occur by diffusion through non-selective porins. However, the expression of two TonB-dependent receptors in A. baumannii under $\mathrm{Zn}$-limiting conditions suggests that transport of $\mathrm{Zn}$ across the outer membrane of this organism may be an energy-dependent process similar to the case in $\mathcal{N}$. meningitidis [51,52]. Transport through TonB-dependent receptors requires the TonB-ExbB-ExbD system, which harnesses energy from the proton motive force generated at the inner membrane to facilitate transport across the outer membrane. Interestingly, A. baumannii encodes two predicted TonB-ExbB-ExbD systems. One of these systems appears to be under transcriptional control by Zur, based on the presence of a Zur-binding consensus sequence within the ton $B$ promoter (Figure 5g). We have designated the putative Zurregulated system TonB1-ExbB1-ExbD1, based on its location within the chromosome relative to the position of the predicted Fur-regulated system. Although TonB1-ExbB1-ExbD1 was previously shown to be up-regulated in the presence of the iron chelator 2,2-dipyridyl, we sought to determine whether Zn-limiting conditions induce expression of the tonB1exbB1exbD1 operon [53]. In the presence of $10 \mu \mathrm{M}$ TPEN, the ton $B$ gene is upregulated 4- to 5-fold supporting a model whereby translocation of $\mathrm{Zn}$ across the outer membrane is an energy-dependent process in A. baumannii (Figure 5h).

Table 2. Locus tags and descriptions of predicted Zur-regulated genes.

\begin{tabular}{|c|c|c|}
\hline Locus tag & Description $^{1}$ & E value $^{2}$ \\
\hline A1S_0145 & Zur (ZnuB, ZnuC) & $6.19 e-08$ \\
\hline A1S_0146 & ZnuA & $9.90 \mathrm{e}-08$ \\
\hline A1S_0391 & LSU ribosomal protein $\mathrm{L} 31 \mathrm{p}$ & $5.74 \mathrm{e}-07$ \\
\hline A1S_0410 & LysR family transcriptional regulator & $3.12 \mathrm{e}-06$ \\
\hline A1S_0452 & TonB (ExbB, ExbD) & $1.17 e-07$ \\
\hline A1S_1679 & Hypothetical protein & $1.42 \mathrm{e}-05$ \\
\hline A1S_2829 & Putative TonB-dependent receptor & $1.84 \mathrm{e}-05$ \\
\hline A1S_2892 & Putative TonB-dependent receptor, ZnuD1 (PId) & $6.19 \mathrm{e}-08$ \\
\hline A1S_3103 & Uncharacterized ABC transporter (possible LPS assembly operon) & $5.74 \mathrm{e}-07$ \\
\hline A1S_3225 & Carbonic anhydrase & $8.83 e-07$ \\
\hline A1S_3411 & Putative metal chaperone involved in $\mathrm{Zn}$ homeostasis & $1.24 \mathrm{e}-08$ \\
\hline A1S_3412 & Hypothetical protein, putative signal peptide & $9.90 \mathrm{e}-08$ \\
\hline A1S 3475 & Putative TonB-dependent receptor protein, ZnuD2 (plasmid pAB2) & $9.90 \mathrm{e}-08$ \\
\hline
\end{tabular}

${ }^{1}$ Description of the predicted protein encoded at the indicated locus. If additional genes are predicted to be part of the same transcriptional unit, their encoded proteins are indicated in parentheses.

${ }^{2}$ Expect values for the zur box motif.

doi:10.1371/journal.ppat.1003068.t002 
ZnuB contributes to the pathogenesis of $A$. baumannii pulmonary infections

To define the contribution of the Znu system to pulmonary infections, we first examined znu promoter activity in both wildtype and S100A9 ${ }^{-1-}$ mice infected with WT::pznuGFP. In both wildtype and S100A $9^{-/-}$mice we observed strong promoter activity as evidenced by GFP signal within lungs harvested at 36 hpi (Figure 6a-f and Figure S5). Although in both wildtype and S100A9 ${ }^{-/-}$mice we detected strong GFP signal, the overall increased bacterial burden in $\mathrm{S} 100 \mathrm{~A} 9^{-/-}$mice led to greater total signal in these sections. These data demonstrate that the $z n u$ genes are expressed in vivo and that $A$. baumannii is $\mathrm{Zn}$ starved in the lung. Furthermore, these data imply that even in the absence of CP, the host sequesters $\mathrm{Zn}$ away from $A$. baumannii suggesting the presence of additional mechanisms for $\mathrm{Zn}$ withholding in the vertebrate lung.

To determine the direct contribution of $\mathrm{ZnuB}$ to A. baumannii pathogenesis, wildtype and S100A $9^{-/-}$mice were co-infected with an equal mixture of wildtype and $\Delta z n u B$ and bacterial burdens were quantified at $36 \mathrm{hpi}$ in lungs and livers. Wildtype $A$. baumannii significantly outcompetes $\Delta z n u B$ for colonization of the lungs of both wildtype and CP-deficient mice (Figure 6g). Notably, $\Delta z n u B$ was only detected in the livers of two mice (10 percent) following intranasal infection (Figure $6 \mathbf{h}$ and Figure S6). Moreover, dissemination of $\Delta z n u B$ to the liver is partially rescued in $\mathrm{S} 100 \mathrm{~A} 9^{-/-}$mice. A similar competition infection comparing wildtype $A$. baumannii to a strain containing a kanamycin resistant cassette in an unrelated gene did not reveal a similar defect, demonstrating that the presence of the kanamycin marker alone is not responsible for the observed phenotype (data not shown). These data suggest that CP-mediated Zn-chelation is critical to limit bacterial dissemination from the primary site of lung infection. Taken together, the results of the in vivo studies demonstrate that $\mathrm{Zn}$ acquisition through $\mathrm{ZnuB}$ contributes to $A$. baumannii pathogenesis. Notably, no significant difference was observed when comparing wildtype and $\Delta z n u B$ in mono-infections (Figure S6B-C).

\section{Zn chelation reverses carbapenem resistance in MDR A. baumannii}

One of the few remaining antibiotic classes available for the treatment of $A$. baumannii infections is the carbapenems. However, carbapenem resistance is becoming increasingly common primarily through dissemination of genes encoding carbapenem hydrolyzing enzymes or carbapenemases [54,55]. Interestingly, many of these carbapenemases are metalloenzymes that require $\mathrm{Zn}$ for their hydrolyzing activity [56,57]. This raises the possibility that $\mathrm{Zn}$ limitation may serve as a valuable adjunct to carbapenem therapy by decreasing carbapenemase activity. To test this hypothesis, we determined the imipenem MIC against the carbapenem resistant clinical isolate, $\mathrm{AB} 0057$, in the presence or absence of $25 \mu \mathrm{M}$ TPEN. Treatment with TPEN reduces the imipenem MIC to below the clinical breakpoint for imipenem resistance in A. baumannii and this effect is reversed by addition of
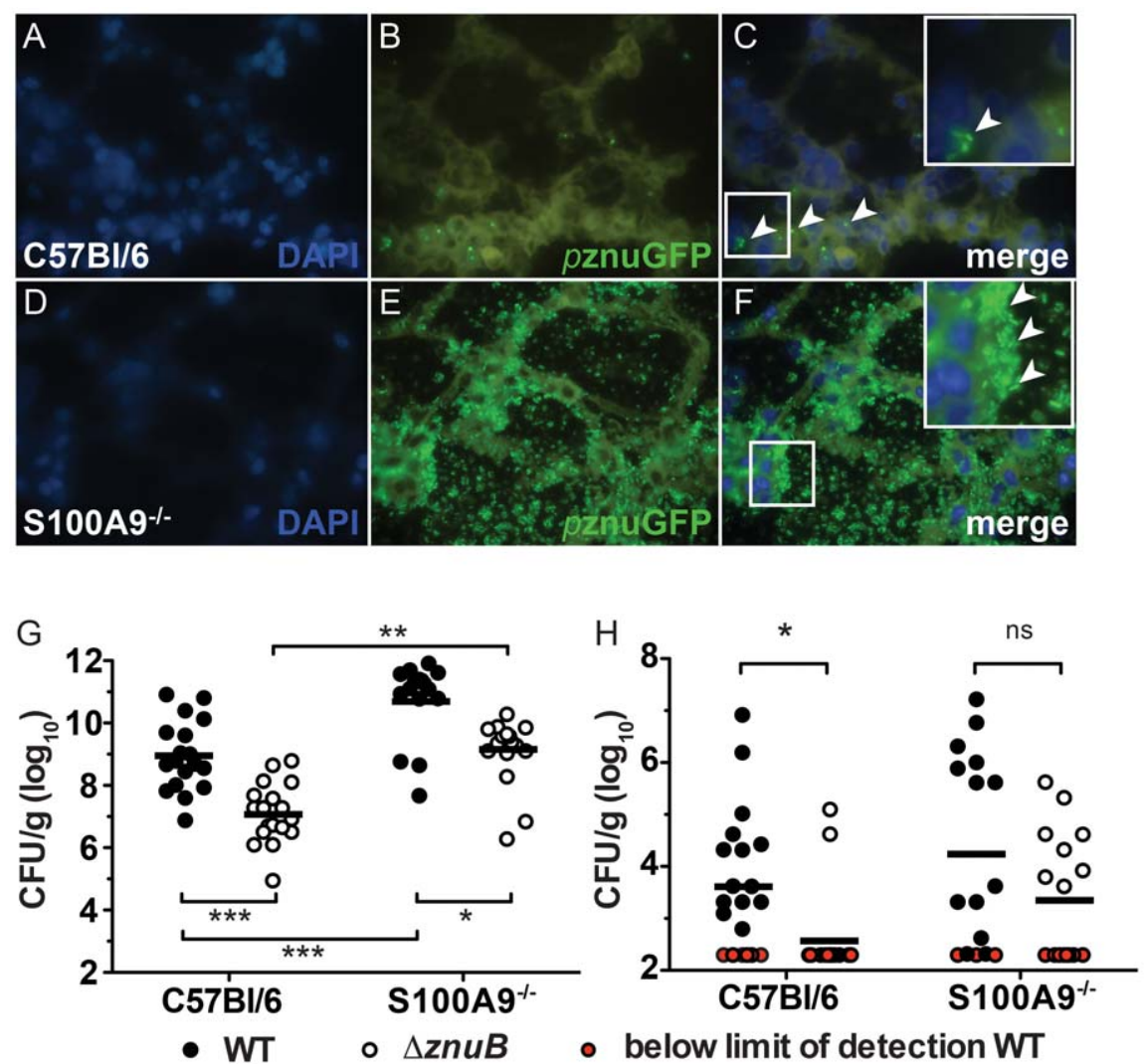

Figure 6. Contribution of the Znu system to pathogenesis in vivo. (A-F) In vivo GFP expression driven by the znu promoter. Frozen sections of lungs harvested at $36 \mathrm{hpi}$ from wildtype $(\mathrm{A}-\mathrm{C})$ or S100A9-1- $(\mathrm{D}-\mathrm{F})$ mice infected with WT::pznuGFP and stained with DAPI. Arrowheads in the merged images indicate bacteria expressing GFP. (G-H) Competition infection between wildtype and $\Delta z n u B$. Bacterial burden in lungs (G) and livers (H) of mice co-infected with wildtype $A$. baumannii and $\triangle$ znuB. Red symbols indicate CFU below the limit of detection. ${ }^{*} p<0.05,{ }^{* *} p<0.01,{ }^{* * *}$ $p<0.001$ as determined by one-way ANOVA. doi:10.1371/journal.ppat.1003068.g006 
excess Zn (Figure 7a). As a control, these experiments were performed with the fluoroquinolone antibiotic, levofloxacin. In AB0057, levofloxacin resistance is mediated by mutations within gyrA (DNA topoisomerase IIA) and parC (DNA topoisomerase IV) and therefore should not be reversed by $\mathrm{Zn}$ chelation [58]. The levofloxacin MIC was either unchanged or slightly increased by $\mathrm{Zn}$ limitation and remained above the breakpoint for clinically defined resistance (Figure $\mathbf{7 b}$ ). These results highlight $\mathrm{Zn}$ limitation as a possible mechanism to combat carbapenem resistance in $A$. baumannii.

\section{Discussion}

Transition metals occupy an essential niche within biological systems. The essentiality of transition metals to invading bacterial pathogens has been exploited by vertebrate hosts as an innate defense strategy. Most work in the area of nutritional immunity has focused on iron sequestration as a mechanism of host defense; however, it is now appreciated that nutritional immunity includes strategies to withhold other essential metals such as $\mathrm{Mn}$ and $\mathrm{Zn}$ $[17,59]$. We have demonstrated that $\mathrm{Mn}$ and $\mathrm{Zn}$ chelation by CP inhibits A. baumannii growth in vitro. We have also determined that $\mathrm{CP}$ is abundant in the lungs of $A$. baumannii-infected mice where it contributes to defense against $A$. baumannii pulmonary infections. Moreover, we have used CP to elucidate physiological processes that are disrupted by $\mathrm{Mn}$ and $\mathrm{Zn}$ chelation by screening a transposon library for mutants with increased or decreased susceptibility to CP. Using this screen we identified a $\mathrm{Zn}$ acquisition system in A. baumannii and defined its $\mathrm{Zn}$-dependent regulation and its roles in $\mathrm{Zn}$ uptake and pathogenesis.

As summarized above, utilizing $\mathrm{CP}$ as a probe has uncovered the ZnuABC $\mathrm{Zn}$ uptake system in A. baumannii. A targeted deletion of $z n u B$ is more sensitive to $\mathrm{CP}$ and other $\mathrm{Zn}$ chelators, particularly in the presence of excess Mn. Notably, the phenotype of the znuB mutant can be rescued by addition of excess $\mathrm{Zn}$, suggesting that $A$. baumannii possesses an additional mechanism to transport $\mathrm{Zn}$ across the inner membrane. Although we did not identify additional inorganic ion transporters in the analysis of the putative Zur regulon, it is possible that $\mathrm{Zn}$ is transported through a low affinity or non-specific transporter. Based on the observation that excess $\mathrm{Mn}$ potentiates the effects of $\mathrm{Zn}$ chelation on $\Delta z n u B$, it is also possible that $\mathrm{Zn}$ acquisition in this mutant depends on an inner membrane Mn transporter. In this case, the presence of excess Mn would occupy Mn transport systems, further reducing $\mathrm{Zn}$ acquisition by $\Delta z n u B$.

Elucidation of the A. baumannii Zur regulon identified genes encoding two putative ZnuD orthologues and a TonB system. These genes were all up-regulated in Zn-limiting conditions. Although it was previously thought that transition metal ions such as $\mathrm{Zn}^{2+}$ and $\mathrm{Mn}^{2+}$ freely diffuse through non-selective porins, the identification of ZnuD in Neisseria spp. suggests that in some bacteria, transport of $\mathrm{Zn}$ across the outer membrane may be an energy-dependent process [51]. A. baumannii strain 17978 has two putative $\mathrm{ZnuD}$ orthologues, one encoded on the chromosome and a second on a plasmid. Moreover, A. baumannii encodes a TonB/ ExbB/ExbD system that is up-regulated in low $\mathrm{Zn}$ conditions suggesting that this energy-generating system may be dedicated to $\mathrm{Zn}$ import. An energy generating system that is activated upon $\mathrm{Zn}$ starvation provides compelling evidence for an energy-dependent mechanism of $\mathrm{Zn}$ transport across the outer membrane. However, it is not yet known whether $\mathrm{ZnuD}$ transports free or chelated $\mathrm{Zn}$. $\mathrm{ZnuD}$ from $\mathcal{N}$. meningitidis contributes to heme acquisition when expressed in E. coli [52]. This finding suggests that ZnuD is either a heme transporter that is up-regulated in low $\mathrm{Zn}$ conditions, or that $\mathrm{ZnuD}$ transports more than one substrate. If the latter is true, $\mathrm{ZnuD}$ may transport $\mathrm{Zn}$ in a chelated form analogous to the siderophore systems used to transport iron. It remains to be determined whether either of the $\mathrm{ZnuD}$ transporters in $A$. baumannii directly transports $\mathrm{Zn}$ or heme.

In addition to the role for $\mathrm{ZnuB}$ in $\mathrm{Zn}$ acquisition and resistance to $\mathrm{CP}$ in vitro, this protein also contributes to pathogenesis in vivo. Specifically, co-infection with wildtype demonstrates that $\Delta z n u B$ is less able to compete with wildtype in vivo. Notably, in the lung, $\triangle z n u B$ exhibits reduced competitive fitness in both wildtype and $\mathrm{CP}$-deficient mice, suggesting that other factors in addition to $\mathrm{CP}$ may contribute to $\mathrm{Zn}$ limitation within the lung. In contrast, the ability of $\Delta z n u B$ to disseminate past the primary site of infection was almost completely abrogated during co-infection with wildtype $A$. baumannii in wildtype mice. However, in CP-deficient mice, $\Delta z n u B$ disseminated efficiently to the liver where bacterial burdens for the mutant approached those for wildtype bacteria. These data suggest that while $\mathrm{CP}$ is an important contributor to innate immunity in the lung, CP may be more important in defending
A

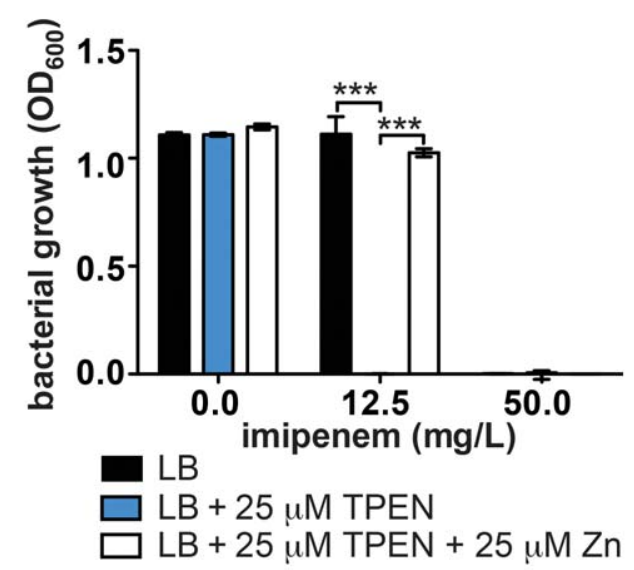

$\mathrm{B}$

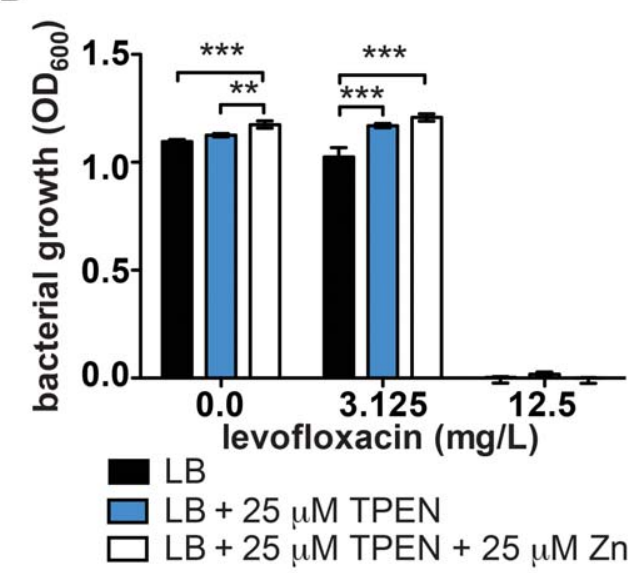

Figure 7. Effect of $\mathrm{Zn}$ chelation on resistance to imipenem and levofloxacin in an MDR isolate of $A$. baumannii. Bacterial growth measured at 24 hours in LB medium in the presence of increasing concentrations of imipenem (A) or levofloxacin (B) and $25 \mu \mathrm{M}$ TPEN, with or without addition of excess $\mathrm{Zn}$. Data for concentrations near and above the clinical breakpoints for resistance are shown. doi:10.1371/journal.ppat.1003068.g007 
against dissemination to secondary sites like the liver. Previous studies have demonstrated an important role for CP in limiting bacterial replication and abscess formation in the liver during $S$. aureus systemic infections [20]. This finding implicates CP as being critical to limit replication in the liver. However, it remains to be determined for $A$. baumannii infections whether CP inhibits bacterial survival in the bloodstream or whether CP is important for protecting against colonization of the liver itself.

Vertebrate hosts have evolved elegant mechanisms to withhold essential metals from invading pathogens. Likewise, bacterial pathogens have evolved efficient means to acquire metals from their vertebrate hosts. Based on these important roles for transition metals at the pathogen-host interface, bacterial metal acquisition systems represent possible targets for therapeutic development. The observation that $\mathrm{Zn}$ limitation reverses imipenem resistance in a carbapenemase-producing clinical isolate suggests that $\mathrm{Zn}$ chelation itself or therapies directed against bacterial $\mathrm{Zn}$ acquisition systems may be viable strategies to use in combination with existing antimicrobial compounds. Given the dire need for new antibiotics effective against MDR A. baumannii, combination strategies like these may be critical in battling this important public health threat.

\section{Materials and Methods}

\section{Ethics statement}

All experiments involving animals were reviewed and approved by the Institutional Animal Care and Use Committee of Vanderbilt University. All experiments were performed according to NIH guidelines, the Animal Welfare Act, and US Federal law.

\section{Bacterial strains and reagents}

All experiments were performed using A. baumannii strain ATCC 17978 (Ab17978) or its derivatives unless otherwise noted. The transposon mutant library was constructed using the EZ-Tn5 transposome system (Epicentre) as described previously [60]. $A$. baumannii strain AB0057 was a gift from Robert Bonomo and is a carbapenemase-producing strain with an imipenem MIC of $>12 \mu \mathrm{g} / \mathrm{ml}$ [58]. Chemicals and antibiotics were purchased from Sigma unless otherwise noted. Recombinant human calprotectin was used for all in vitro experiments and was expressed and purified as described previously [20]. All experiments involving liquid cultures were performed at $37^{\circ} \mathrm{C}$ with shaking at $180 \mathrm{rpm}$ unless otherwise specified.

\section{In vitro growth inhibition assays with calprotectin}

Overnight cultures of $A$. baumannii were diluted 1:20 in Chelextreated RPMI (ChxRPMI) without metals added back and incubated for 1 hour at $37^{\circ} \mathrm{C}$. Following incubation, the cultures were further diluted 1:50 in CP growth media, which consists of 20 percent CP buffer (20 mM Tris, pH 7.5, $100 \mathrm{mM} \mathrm{NaCl,} 10 \mathrm{mM}$ $\beta$-mercaptoethanol, $3 \mathrm{mM} \mathrm{CaCl} 2$ ), and 80 percent ChxRPMI to

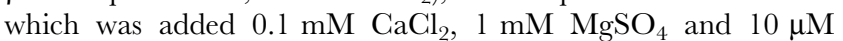
$\mathrm{FeSO}_{4}$, with increasing concentrations of $\mathrm{CP}(0-400 \mu \mathrm{g} / \mathrm{ml})$. In some assays, $\mathrm{Mn}$ and/or $\mathrm{Zn}$ were also added at the indicated concentrations. Bacteria were incubated at $37^{\circ} \mathrm{C}$ and growth was monitored at 1- to 2-hour intervals throughout the time course. Bacterial growth in the presence of $\mathrm{CP}$ was normalized to growth without CP and dose-response curves were generated by nonlinear regression analyses. $\mathrm{IC}_{50}$ values were obtained from the best-fit curves of data obtained after 10-12 hours of culture.

\section{ICP-MS analyses of intracellular $\mathrm{Zn}$ concentrations}

Bacteria were cultured overnight in ChxRPMI with $0.1 \mathrm{mM}$ $\mathrm{CaCl}_{2}, 1 \mathrm{mM} \mathrm{MgSO}{ }_{4}$ and $10 \mu \mathrm{M} \mathrm{FeSO}_{4}$ added. Bacteria were sub-cultured 1:20 in fresh ChxRPMI for 1 hour. The bacteria were then sub-cultured 1:50 into $10 \mathrm{~mL} \mathrm{CP}$ growth media with 0 or $37.5 \mu \mathrm{g} / \mathrm{ml} \mathrm{CP}$ and $50 \mu \mathrm{M} \mathrm{Mn}$ and incubated for approximately 6 hours $\left(\mathrm{OD}_{600}=0.6\right)$. Bacteria were then pelleted by centrifugation (10 minutes, $6,000 \mathrm{~g})$, washed twice with water and transferred to Teflon vials. Bacterial pellets were dried by incubation at $50^{\circ} \mathrm{C}$ overnight then digested by boiling in nitric acid for 6 hours at $130^{\circ} \mathrm{C}$.

Elemental quantification was performed on the Thermo Element 2 HR-ICPMS (Thermo Fisher Scientific, Bremen, Germany) coupled with ESI auto sampler (Elemental Scientific, Omaha, NE). The HR-ICPMS is equipped with a PFA microflow nebulizer (Elemental Scientific, Omaha, NE), a double channel spray chamber (at room temperature), a magnetic sector followed by an electric sector, and a second electron multiplier. The sample uptake was achieved through self-aspiration via $0.25 \mathrm{~mm}$ ID sample probe and sample capillary. The operation parameters are listed in Table 3.

Results were normalized to the dry weight of the sample measured prior to analysis. Quantities of Mn, $\mathrm{Zn}$ and Fe were then normalized to $\mathrm{Cu}$ as an internal reference since $\mathrm{Cu}$ levels were not altered by CP treatment (data not shown).

\section{A. baumannii infections}

Wildtype C57BL/6 mice were obtained from Jackson Laboratories. S100A $9^{-1-}$ mice were a gift from Wolfgang Nacken (Institute of Experimental Dermatology, University of Münster, 48149 Münster, Germany). All of the infection experiments were approved by the Vanderbilt University Institutional Animal Care and Use Committee. In vivo studies utilized the murine model of $A$. baumannii pneumonia previously developed in our laboratory with a few modifications [60]. Briefly, mice were infected with 3$5 \times 10^{8} \mathrm{CFU}$ A. baumannii in $50 \mu \mathrm{l}$ PBS. At the indicated times post infection mice were euthanized and CFU were enumerated in lungs and livers following tissue homogenization and plating on bacterial growth medium. We initially performed time course studies comparing male C57BL/6 mice with S100A9 $9^{-/-}$mice for their susceptibilities to $A$. baumannii infection to determine the optimal age at which to perform experiments (data not shown). Based on these studies, 9-10 week-old male mice were used for subsequent experiments. For infections comparing wildtype and $\triangle z n u B$, bacteria were cultured in RPMI instead of LB. For coinfections, equal numbers of wildtype and $\Delta z n u B$ were mixed to yield a total of $1 \times 10^{10} \mathrm{CFU} / \mathrm{ml}$ and mice were infected with $50 \mu \mathrm{l}$ of the combined mixture. At 36 or 72 hours post infection (hpi),

Table 3. HR-ICP-MS parameters.

\begin{tabular}{ll}
\hline Instrument & Element 2 HR-IC-MS \\
\hline RF power & $1200 \mathrm{~W}$ \\
Cool gas & $16.00 \mathrm{~L} \mathrm{~min}^{-1}$ \\
Auxiliary gas & $0.8 \mathrm{~L} \mathrm{~min}{ }^{-1}$ \\
Sample gas & $1.05 \mathrm{~L} \mathrm{~min}^{-1}$ \\
Resolution mode & Medium resolution $(4000)$ \\
Isotopes measured & ${ }^{55} \mathrm{Mn}^{57} \mathrm{Fe}^{63} \mathrm{Cu}^{65} \mathrm{Cu}^{66} \mathrm{Zn},{ }^{68} \mathrm{Zn}$ \\
Runs & 10 \\
Passes & 1 \\
Samples per peak & 20 \\
Sample time & $0.01 \mathrm{~s}$ \\
\hline doi:10.1371/journal.ppat.1003068.t003
\end{tabular}


mice were euthanized and differential bacterial counts were determined in lungs and livers by plating organ homogenates on LB agar or LB agar supplemented with $40 \mu \mathrm{g} / \mathrm{ml}$ kanamycin. To calculate the competitive index, the ratio of $\Delta z n u B$ to wildtype bacteria recovered from lungs and livers was divided by the input ratio. When no bacteria (either wildtype, $\Delta z n u B$ or both) were recovered, the number of recovered bacteria was set at the limit of detection for the assay (approximately $600 \mathrm{CFU} / \mathrm{g}$ for lungs and $200 \mathrm{CFU} / \mathrm{g}$ for livers). For histological analyses lungs were inflated with $1 \mathrm{ml}$ of 10 percent formalin, fixed, embedded and stained as described previously [60]. For Imaging Mass Spectrometry and GFP reporter assays, mice were infected as described above with wildtype bacteria or WT::pznuGFP (described below). Upon sacrifice, lungs were perfused with a 1:1 mixture of water and Optimal Cutting Temperature (OCT) compound (TissueTek). Lobes were marked using dye-based drawing ink, and snap frozen using a mixture of hexanes and dry ice. Organs were stored at $-80^{\circ} \mathrm{C}$ until ready for use.

\section{Imaging mass spectrometry of infected and uninfected lungs}

Trifluoroacetic acid (TFA) and Sinapinic Acid were purchased from Sigma-Aldrich Chemical Co. (St. Louis, MO, USA). HPLCgrade acetonitrile, Ammonium bicarbonate powder, and technical grade hexanes were purchased from Fisher Scientific (Pittsburgh, PA, USA). OCT was purchased from VWR International (Suwanee, GA, USA). Dye-based drawing ink was purchased from Higgins Ink (Chartpak Inc. Leeds, MA, USA). Phosphate Buffered Saline $(10 \times)$ was purchased from Life Technologies Corporation (Grand Island, NY, USA).

Frozen lung tissue was cut into $10 \mu \mathrm{m}$ thick sections at $-20^{\circ} \mathrm{C}$ using a cryostat (Leica Microsystems, Bannockburn, IL, USA) and thaw mounted onto an indium-tin oxide (ITO) coated glass slide (Delta Technologies, Loveland, CO, USA). Mounted tissue sections were washed to remove excess lipids and salts using sequential chilled solutions of phosphate buffered saline, $100 \mathrm{mM}$ ammonium bicarbonate, and 95 percent ethanol, all performed cold. Sinapinic acid matrix was prepared at $20 \mathrm{mg} / \mathrm{ml}$ in $1: 1$ acetonitrile:water with $0.1 \%$ TFA. Matrix was applied to tissue using a Portrait 630 (Labcyte, Sunnyvale, CA, USA) acoustic robotic microspotter. Matrix was applied in a block pattern with each spot being $200 \mu \mathrm{m}$ in diameter and spaced $250 \mu \mathrm{m}$ apart center to center, using three passes of fifteen $170 \mathrm{pL}$ drops.

Spotted arrays were imaged using a Bruker Autoflex Speed time-of-flight mass spectrometer (Bruker Daltonics, Billerica, MA, USA) in linear positive-ion mode equipped with a SmartBeam laser (Nd:YAG, $355 \mathrm{~nm}$ ). Detector voltage gain was set to 2910 volts. Spectra were collected at each spot as a sum of 400 laser shots in 50 shot steps. The laser repetition rate was $1,000 \mathrm{~Hz}$, first and second ion source voltages were $19.47 \mathrm{kV}$ and $17.82 \mathrm{kV}$ respectively with a delay time of $350 \mathrm{~ns}$ and a lens voltage of $6 \mathrm{kV}$. Measured mass range was from 3,000-27,000 Daltons. Spectra were analyzed using Fleximaging 3.0 Software (Bruker Daltonics) and were normalized to total ion current. Ion density maps were extracted.

\section{Transposon mutant library screen}

A transposon library was constructed using the EZ-Tn5 transposome system as described previously [60]. Since growth of wildtype bacteria is significantly attenuated in ChxRPMI without $\mathrm{Mn}$ or $\mathrm{Zn}$ added back, the growth conditions were modified for the primary screen in order to facilitate rapid screening of over 4000 mutants. Mutants were inoculated directly from frozen stocks into $\mathrm{LB}$ and incubated at $37^{\circ} \mathrm{C}$ overnight.
Bacteria were then sub-cultured at a 1:20 dilution in ChxRPMI for 1 hour at room temperature. Following the 1-hour subculture, bacteria were diluted 1:50 into 96-well plates containing $100 \mu \mathrm{l}$ of CP screening media, which consisted of 50 percent RPMI (not chelex-treated) without supplemental metals and 50 percent CP $(40 \mu \mathrm{g} / \mathrm{ml})$ in $\mathrm{CP}$ buffer. The plates were incubated at $37^{\circ} \mathrm{C}$ with shaking at $180 \mathrm{rpm}$ for 10-12 hours, and growth was monitored by measuring the optical density of the cultures at $600 \mathrm{~nm}$. Mutants whose growth in the presence of CP differed by more than two standard deviations from the plate average were selected for further analysis. The phenotypes of the selected mutants were confirmed by repeating the inhibition assay as described above for the primary screen in triplicate cultures. Only mutants that exhibited growth comparable to wildtype in media without CP but whose growth in the presence of CP differed significantly from that of wildtype bacteria were selected for insert identification. The transposon insertion sites were determined by inverse PCR or by sequencing directly from chromosomal DNA using primers KAN1 (5' - ACGTACAACAAAGCTCTCATCAACC - $\left.3^{\prime}\right)$ and KAN2 (5' - CTACCGTGTGGAACACGTACATCT - 3').

\section{Construction of $\triangle z n u B$}

Approximately $1000 \mathrm{bp}$ of flanking DNA sequence was amplified from the immediate $5^{\prime}$ and $3^{\prime}$ regions surrounding $z n u B$. The kanamycin resistance gene aph was amplified from pUCK 1 and the three PCR products were stitched by overlap extension PCR as described previously [61]. This PCR product was cloned into pCR2.1 (Invitrogen) and sequence verified. The product was then re-amplified and the resulting linear DNA product was transformed into Abl7978 to generate an in-frame allelic replacement of $z n u B$ with $a p h$. Transformants were selected on LB agar supplemented with $40 \mu \mathrm{g} / \mathrm{ml}$ kanamycin. The resulting colonies were screened for integration of the kanamycin cassette into the correct locus using locus-specific primers that anneal outside the region contained within the knock out construct.

\section{In vitro growth inhibition assays with TPEN}

Overnight bacterial cultures were sub-cultured 1:20 in fresh LB for 1 hour followed by a 1:50 back dilution into LB containing various concentrations of tetrakis-(2-pyridylmethyl)ethylenediamine (TPEN) $(0-100 \mu \mathrm{M})$ with or without addition of $100 \mu \mathrm{M}$ $\mathrm{ZnSO}_{4}$. Bacterial growth was assessed over approximately 24 hours. Data from the 12-hour time point, which are representative of the trends in bacterial growth over the full time course, are shown. Data were averaged from at least three biological replicates and statistical significance was determined by one-way ANOVA.

\section{Complementation of the TPEN sensitivity of $\triangle z n u B$}

A vector for complementation was constructed by first amplifying the region separating znuA and zurznuCB by PCR using primers ZnuProl (5' - CGGAATTCGACAGACGATCAATTAGTAATAGC - 3') and ZnuPro2 (5' - CGGAATTCAAGAACTGATCATAGACATAACATC $-3^{\prime}$ ). The resulting product was cloned into the EcoRI site of the A. baumannï: E. coli shuttle vector pWH1266 to generate pznuPro. The open reading frame encoding $z n u B$ was PCR amplified from WT genomic DNA using primers znuBcompF2 (5' - CCGGGATCGATGATGGAATGGTTACAATTATTG - $\left.3^{\prime}\right)$ and znuBcompR2 (5' CGGGTCGACGATTTAGGGTGGTTGAGTTTG - 3'), which include BamHI and SalI sites, respectively. The resulting product was cloned into the BamHI and SalI sites of pznuPro to generate the $\mathrm{p} z n u B$ vector used for complementation experiments. The 
empty vector, $\mathrm{p} z n u$ Pro, and the complementation vector, $\mathrm{p} z n u B$, were each introduced into $\Delta z n u B$ by electroporation. In addition, the empty vector was also transformed into wildtype bacteria to serve as an additional control. For growth assays, bacteria were grown overnight in $\mathrm{LB}+500 \mu \mathrm{g} / \mathrm{ml}$ ampicillin with aeration at $37^{\circ} \mathrm{C}$, and the next morning, overnight bacterial cultures were sub-cultured $1: 50$ in fresh $\mathrm{LB}+500 \mu \mathrm{g} / \mathrm{ml}$ ampicillin for an additional hour. These cultures were then re-seeded 1:100 into $\mathrm{LB}+500 \mu \mathrm{g} / \mathrm{ml}$ ampicillin and containing various concentrations of TPEN $(0-80 \mu \mathrm{M})$ on a 96-well plate. Bacterial growth was assessed by $\mathrm{OD}_{600}$ over 24 hours with aeration at $37^{\circ} \mathrm{C}$. Data are presented from the 12-hour time point, which are representative of the trends in bacterial growth over the full time course. Statistical significance was determined by one-way ANOVA.

\section{Construction of a znu reporter and measurement of GFP expression}

The gene encoding GFP was sub-cloned from pMU125 into the BamHI and SalI sites of pznuPro to generate pznuGFP, which was subsequently introduced into wildtype and $\Delta z n u B$ by electroporation. Empty pWH1266 was included as a control. The resulting strains, designated as WT::pWH1266, WT::pznuGFP, and $\Delta z n u B:$ :pznuGFP were cultured in LB with increasing concentrations of TPEN as described above or with increasing concentrations of $\mathrm{Zn}(0-1000 \mu \mathrm{M})$ and GFP fluorescence was measure using a BioTeq plate reader with excitation and emission filters set for 395 and $509 \mathrm{~nm}$, respectively. GFP fluorescence was normalized to bacterial growth, and data from approximately 9 hours of growth are shown. Data were averaged from three biological replicates.

\section{Identification of a putative Zur-binding consensus sequence and Zur-regulated genes}

The intergenic region between $z n u A$ and zur was searched for possible Zur binding motifs using the consensus 19 bp zur box (AATGTTATAWTATAACATT) derived from the analysis of 13 genes from several gamma-Proteobacteria [48]. BLAST analysis was then employed to search for this A. baumannii zur box in the Ab17978 genome. Once possible Zur-regulated genes were identified, 5' flanking sequences from each gene were searched for motifs using the Multiple Em for Motif Elicitation (MEME) tool [62]. The search parameters were limited to search for motifs on the forward strand only and to motifs ranging from 12 to 50 nucleotides in length. This search independently identified the putative zur box motifs from the majority of genes analyzed. Each of the zur box sequences was then entered into WebLogo 2.0 to generate a sequence logo that graphically represents the degree of sequence conservation at each nucleotide position [63].

\section{Zur expression and purification}

A. baumannii zur was PCR amplified using primers $167 \times 2\left(5^{\prime}-\right.$ CGGCTCGAGTTAGGGAGCTGTGGGG-3') and $167 \times 4$ (5'CGGCTCGAGGTTATGTCTATGATGAGTTCTTGC-3')

and cloned into pET15b (Novagen) in frame with the N-terminal 6xHis tag. E. coli BL21(DE3) cells were transformed with the Zur expression vector and grown at $37^{\circ} \mathrm{C}$ to an $\mathrm{OD}_{600}$ of 0.6 before induction with $0.5 \mathrm{mM}$ IPTG. Following induction, bacteria were maintained at $37^{\circ} \mathrm{C}$ for an additional 6 hours. Cells were harvested by centrifugation at $6000 \mathrm{~g}$ and resuspended in lysis buffer $\left(50 \mathrm{mM} \mathrm{NaH} \mathrm{PO}_{4}, 300 \mathrm{mM} \mathrm{NaCl}, 20 \mathrm{mM}\right.$ imidazole, $1 \mathrm{mg} / \mathrm{ml}$ lysozyme). Cells were lysed by five passes through an EmulsiFlex homogenizer (Aventin, Inc., Ottawa, ON) at 20,000 psi. Following disruption the lysates were centrifuged at
$8,000 \times g$ to remove unlysed cells and debris. Insoluble material was separated by ultracentrifugation at $100,000 \times \mathrm{g}$ for 1 hour at $4^{\circ} \mathrm{C}$. The resulting supernatants were applied to a Ni: NTA column pre-equilibrated with lysis buffer. The column was washed with approximately 20 bed volumes of wash buffer $\left(50 \mathrm{mM} \mathrm{NaH}_{2} \mathrm{PO}_{4}\right.$, $300 \mathrm{mM} \mathrm{NaCl}, 25 \mathrm{mM}$ imidazole) followed by sequential washes with increasing concentrations of imidazole $(50 \mathrm{mM}, 100 \mathrm{mM}$, $150 \mathrm{mM}, 175 \mathrm{mM}, 200 \mathrm{mM}, 225 \mathrm{mM}$ and $250 \mathrm{mM}$ ). Zur eluted free from contaminating proteins in buffer containing between 200 and $250 \mathrm{mM}$ imidazole. $\mathrm{CaCl}_{2}$ was added to the eluted sample to a final concentration of $2.5 \mathrm{mM}$. Removal of the His tag was achieved by thrombin cleavage. Briefly, two units of restriction grade thrombin (Novagen) were added and the sample was cleaved and dialyzed overnight at $4^{\circ} \mathrm{C}$ into buffer containing $20 \mathrm{mM}$ Tris-HCl, pH 8.0, $150 \mathrm{mM} \mathrm{NaCl}$ and $2.5 \mathrm{mM} \mathrm{CaCl}_{2}$.

\section{PAR assay for $\mathrm{Zn}$ binding}

$\mathrm{Zn}$ binding by Zur was determined using the Zn-binding dye PAR. Free PAR exhibits a peak absorbance at approximately $410 \mathrm{~nm}$, which shifts to $500 \mathrm{~nm}$ upon $\mathrm{Zn}$ binding. To determine if Zur binds $\mathrm{Zn}$, increasing concentrations $(0 \mu \mathrm{M}-4 \mu \mathrm{M})$ of purified Zur were added to solutions containing $10 \mu \mathrm{M}$ PAR and $5 \mu \mathrm{M} \mathrm{Zn}$ in $50 \mathrm{mM}$ HEPES, $\mathrm{pH}$ 8.0. Spectra were obtained for free PAR and PAR bound to $\mathrm{Zn}$ as controls, which were compared to the spectra obtained in the presence of Zur. A decrease in the absorbance at $500 \mathrm{~nm}$, together with an increase in the absorbance at $410 \mathrm{~nm}$ indicates binding of $\mathrm{Zn}$ by Zur.

\section{Electrophoretic mobility shift assays}

EMSA probes were generated from primers zurl $\left(5^{\prime}-\right.$ CGAAGCATGTTATAATATAACAAAGTTAC $\left.-3^{\prime}\right)$ and zur2 (5'-GTAACTTTGTTATATTATAACATGCTTCG - 3') for the znuA/zurznuCB Zur box or zurnegl $\left(5^{\prime}\right.$ - GTTACAAAAATACGTAAGATTAATCGAAT - 3') and zurneg2 (5' - ATTCGATTAATCTTAGGTATTTTTGTAAC - $3^{\prime}$ ) for the intragenic sequence from $z n u A$ that served as a negative control. Each primer was incubated at $65^{\circ} \mathrm{C}$ for $10 \mathrm{~min}$ then incubated in a water bath that was allowed to slowly equilibrate from $65^{\circ} \mathrm{C}$ to room temperature. Increasing concentrations of purified Zur $(0-$ $2500 \mathrm{nM}$ ) were incubated with $250 \mathrm{nM}$ of the probes described above in EMSA buffer (20 mM Tris- $\mathrm{HCl}, \mathrm{pH} 8.0,50 \mathrm{mM} \mathrm{KCl}$, $1 \mathrm{mM} \mathrm{DTT,} \mathrm{5 \%} \mathrm{glycerol} \mathrm{and} 100 \mu \mathrm{M} \mathrm{ZnCl}_{2}$ ) for $20 \mathrm{~min}$ at room temperature. Following incubation, $20 \mu \mathrm{l}$ of each sample was loaded onto $4 \%$ polyacrylamide gels and electrophoresed for $30 \mathrm{~min}$ at $100 \mathrm{~V}$. The gels were stained with SYBR green (Invitrogen) and visualized on an Alpha Imager gel documentation system using UV light. In order to test whether Zn chelation could eliminate Zur binding to target DNA, $250 \mathrm{nM}$ of Zur target DNA was incubated with $1250 \mathrm{nM}$ Zur in EMSA buffer with increasing concentrations of EDTA $(0-2500 \mu \mathrm{M})$. EDTA was chosen as a chelator for these assays since it has higher solubility in water than TPEN.

\section{Expression analyses}

A. baumannii was grown in LB or LB supplemented with $10 \mu \mathrm{M}$ TPEN for approximately 6 hours at $37^{\circ} \mathrm{C}$ with shaking at $180 \mathrm{rpm}$. This concentration was selected because at this concentration of TPEN $\Delta z n u B$ begins to exhibit decreased growth compared to wildtype bacteria. This suggests that the Znu system is required for optimal growth under these conditions and is therefore likely to be induced under these conditions in wildtype bacteria. Reverse transcription was carried out on $2 \mu \mathrm{g}$ total RNA using 200 units M-MLV reverse transcriptase and $1 \mu \mathrm{g}$ random hexamers according to the manufacturer's protocol (Promega, 
Table 4. Primers used for $q P C R$.

\begin{tabular}{ll}
\hline Target gene & Primer sequences \\
\hline znuA & GAGTACGTTAGGTGGAGTCAGG \\
znuB & GGTCATCCGTAAGGCACC \\
& TGGCACATGGAACCTACTTG \\
znuC & AACACTGACACCGAGTGAGC \\
& CATCTCATAGTCTCCTTACGG \\
znuD1 & TGTGAGGTCTGCTATTGTGAGG \\
znuD2 & CAAGTTGCATTACGTGTGAGG \\
& AATGGACTAACTCAATACGCCC \\
tonB1 & GCGTACCTAATCTTGACTCTGC \\
& GTCATCACGGCACTAATTGCG \\
\hline doi:10.1371/journal.ppat.1003068.t004
\end{tabular}

Madison, WI). PCR was performed using $10 \mathrm{ng}$ cDNA template (0.01 ng template for $16 \mathrm{~S}$ rRNA). Control reactions were performed on RNA samples without reverse transcriptase treatment. These reactions did not yield detectable signal. Sequences for the primers used in these analyses are shown in Table 4. Data were analyzed from at least three biological replicates after normalizing to $16 \mathrm{~S}$ rRNA. Data from TPEN treated samples are presented as the fold-induction relative to untreated samples.

\section{In vivo GFP reporter activity}

Frozen lungs of mice infected with wildtype or WT::pznuGFP were sectioned as described above and stained with DAPI $(0.01 \mathrm{ng} / \mathrm{ml})$ for 30 minutes at room temperature. Sections were washed with PBS, and coverslips were sealed over the sections using clear nail polish. The sections were visualized using an Olympus BX60 microscope. Images were captured with an Olympus DP71 camera using DP Controller and analyzed using DP Manager software.

\section{Imipenem and levofloxacin inhibition assays}

Bacteria were cultured in LB overnight then sub-cultured 1:1000 in LB containing $25 \mu \mathrm{M}$ TPEN and either imipenem $(0-20 \mu \mathrm{g} / \mathrm{ml})$ or levofloxacin $(0-25 \mu \mathrm{g} / \mathrm{ml})$. Where indicated, $\mathrm{ZnSO}_{4}$ was added to a final concentration of $25 \mu \mathrm{M}$. Bacteria were cultured for 24 hours while the optical densities of the cultures were monitored at $600 \mathrm{~nm}$. Minimum inhibitory concentrations were determined as the concentration in the first well in which no bacterial growth was observed. MICs were comparable for each of the antibiotics in LB as compared to Mueller Hinton Broth (data not shown).

\section{Supporting Information}

Figure S1 A. baumannii growth in the presence of increasing concentrations of CP (solid lines) or $\Delta \mathrm{SI} / \mathrm{SII}$, a variant of CP that no longer binds $\mathrm{Mn}$ and $\mathrm{Zn}$ (dashed lines). Black indicates no $\mathrm{Mn}$ or $\mathrm{Zn}$ added, while orange indicates $25 \mu \mathrm{M} \mathrm{Mn}$ and $25 \mu \mathrm{M} \mathrm{Zn}$ added back. Data represent the average of three biological replicates.

(TIF)
Figure S2 Bacterial burdens in lungs of wildtype and $\mathrm{S} 100 \mathrm{~A} 9^{-/}$ mice harvested at $72 \mathrm{hpi}$ with $A$. baumannii. Each symbol represents one animal. Only data from mice surviving to 72 hours are shown. The data were combined from two independent experiments with at least 10 mice per experiment per genotype. (TIF)

Figure S3 CP growth inhibition assays comparing wildtype with $\Delta z n u B$. Bacteria were cultured in CP growth media in the presence of increasing concentrations of $\mathrm{CP}$ without supplementation (A) or with addition of $25 \mu \mathrm{M} \mathrm{Zn}(\mathrm{B}), 25 \mu \mathrm{M} \mathrm{Mn}(\mathrm{C})$ or both $25 \mu \mathrm{M} \mathrm{Zn}$ and $25 \mu \mathrm{M} \mathrm{Mn}(\mathrm{D})$. Data are presented as the percent growth relative to bacterial growth without CP. Curve fit was performed using a non-linear regression with variable slope. Curves are not drawn for $\mathrm{WT}+\mathrm{Mn}$ and $\mathrm{WT}+\mathrm{Zn}$ and $\mathrm{Mn}$ because these data are not converged and therefore the same curve fit parameters could not be used. Data are the average of three independent experiments with at least three biological replicates each.

(TIF)

Figure S4 Growth curve analyses of wildtype and $\Delta z n u B$ cultured in CP growth media with (orange) or without (black) added $\mathrm{Mn}$ and $\mathrm{Zn}$. Data are averaged from at least three biological replicates. Error bars, which may be obscured by the symbols in some cases, represent one standard deviation from the mean.

(TIF)

Figure S5 In vivo GFP expression driven by the znu promoter. Frozen sections of lungs harvested at 36 hpi from wildtype (A-D) or $\mathrm{S} 100 \mathrm{~A} 9^{-/-}(\mathrm{E}-\mathrm{H})$ mice infected with WT::pznuGFP and stained with DAPI. Sections from lungs of mice infected with wildtype bacteria without the pznuGFP plasmid (I-L) are shown for comparison.

(TIF)

Figure S6 (A) Competitive indices of $\Delta z n u B$ compared to wildtype $A$. baumannii in lungs and livers of wildtype and S100A $9^{-/-}$mice. Each symbol represents one animal. Red symbols indicate mice in which the competitive index was determined by setting the recovered CFU for $\Delta z n u B$ at the limit of detection since there were no recoverable CFU of $\Delta z n u B$ in these mice. (B-C) Bacterial burdens from monoinfections in lungs (B) and livers $(\mathbf{G})$ of wildtype and S100A $9^{-/-}$mice harvested at 36 hpi with either wildtype (black symbols) or $\Delta z n u B$ (open symbols) A. baumannii. Each symbol represents one animal. The data were combined from two independent experiments with 5-10 mice per experiment per genotype.

(TIF)

\section{Acknowledgments}

We thank members of the Skaar laboratory for critical review of the manuscript. We thank Luis Actis (Miami University) for providing $A$. baumannii: E. coli shuttle vectors and Robert Bonomo (Case Western Reserve University) for providing A. baumannii strain AB0057.

\section{Author Contributions}

Conceived and designed the experiments: MIH EPS. Performed the experiments: MIH BLM JLM YZ TEK. Analyzed the data: MIH BLM JLM YZ EPS. Contributed reagents/materials/analysis tools: NS WJC RMC EPS. Wrote the paper: MIH EPS. 


\section{References}

1. Gaynes R, Edwards JR, System NNIS (2005) Overview of nosocomial infections caused by gram-negative bacilli. Clin Infect Dis 41: 848-854.

2. Erdem I, Ozgultekin A, Sengoz Inan A, Dincer E, Turan G, et al. (2008) Incidence, etiology, and antibiotic resistance patterns of gram-negative microorganisms isolated from patients with ventilator-associated pneumonia in a medical-surgical intensive care unit of a teaching hospital in Istanbul, Turkey (2004-2006). Jpn J Infect Dis 61: 339-342.

3. Garza-González E, Llaca-Díaz JM, Bosques-Padilla FJ, González GM (2010) Prevalence of multidrug-resistant bacteria at a tertiary-care teaching hospital in Mexico: special focus on Acinetobacter baumannii. Chemotherapy 56: 275-279.

4. Jean S-S, Hsueh P-R (2011) High burden of antimicrobial resistance in Asia. Int J Antimicrob Agents 37: 291-295.

5. Jean S-S, Hsueh P-R, Lee W-S, Chang H-T, Chou M-Y, et al. (2009) Nationwide surveillance of antimicrobial resistance among non-fermentative Gram-negative bacteria in Intensive Gare Units in Taiwan: SMART programme data 2005. Int J Antimicrob Agents 33: 266-271.

6. Vincent J-L, Rello J, Marshall J, Silva E, Anzueto A, et al. (2009) International study of the prevalence and outcomes of infection in intensive care units. JAMA 302: 2323-2329.

7. Jawad A, Seifert H, Snelling AM, Heritage J, Hawkey PM (1998) Survival of Acinetobacter baumannii on dry surfaces: comparison of outbreak and sporadic isolates. J Clin Microbiol 36: 1938-1941.

8. Fuangthong M, Julotok M, Chintana W, Kuhn K, Rittiroongrad S, et al. (2011) Exposure of Acinetobacter baylyi ADP1 to the biocide chlorhexidine leads to acquired resistance to the biocide itself and to oxidants. J Antimicrob Chemother 66: $319-322$

9. Kawamura-Sato K, Wachino J-i, Kondo T, Ito H, Arakawa Y (2010) Correlation between reduced susceptibility to disinfectants and multidrug resistance among clinical isolates of Acinetobacter species. J Antimicrob Chemother 65: 1975-1983.

10. Rajamohan G, Srinivasan VB, Gebreyes WA (2009) Biocide-tolerant multidrugresistant Acinetobacter baumanmii clinical strains are associated with higher biofilm formation. J Hosp Infect 73: 287-289.

11. Apisarnthanarak A, Mundy LM (2009) Mortality associated with Pandrugresistant Acinetobacter baumannii infections in Thailand. Am J Infect Control 37: 519-520.

12. Chan P-C, Huang L-M, Lin H-C, Chang L-Y, Chen M-L, et al. (2007) Control of an outbreak of pandrug-resistant Acinetobacter baumannii colonization and infection in a neonatal intensive care unit. Infect Control Hosp Epidemiol 28: 423-429.

13. Falagas ME, Bliziotis IA (2007) Pandrug-resistant Gram-negative bacteria: the dawn of the post-antibiotic era? Int J Antimicrob Agents 29: 630-636.

14. Falagas ME, Rafailidis PI, Matthaiou DK, Virtzili S, Nikita D, et al. (2008) Pandrug-resistant Klebsiella pneumoniae, Pseudomonas aernginosa and Acinetobacter baumannii infections: characteristics and outcome in a series of 28 patients. Int J Antimicrob Agents 32: 450-454

15. Souli M, Galani I, Giamarellou H (2008) Emergence of extensively drugresistant and pandrug-resistant Gram-negative bacilli in Europe. Euro Surveill 13: pii: 19045

16. Mortensen BL, Skaar EP (2012) Host-microbe interactions that shape the pathogenesis of Acinetobacter baumannii infection. Cell Microbiol 14: 1336-44.

17. Hood MI, Skaar EP Nutritional immunity: transition metals at the pathogenhost interface. Nat Rev Microbiol 10: 525-37.

18. Weinberg ED (1975) Nutritional immunity. Host's attempt to withold iron from microbial invaders. JAMA 231: 39-41.

19. Weinberg ED (2009) Iron availability and infection. Biochim Biophys Acta 1790: 600-605.

20. Corbin BD, Seeley EH, Raab A, Feldmann J, Miller MR, et al. (2008) Metal chelation and inhibition of bacterial growth in tissue abscesses. Science 319: 962-965.

21. Bianchi M, Niemiec MJ, Siler U, Urban GF, Reichenbach J (2011) Restoration of anti-Aspergillus defense by neutrophil extracellular traps in human chronic granulomatous disease after gene therapy is calprotectin-dependent. J Allergy Clin Immunol 127: 1243-1252.e1247.

22. Kehl-Fie TE, Chitayat S, Hood MI, Damo S, Restrepo N, et al. (2011) Nutrient metal sequestration by calprotectin inhibits bacterial superoxide defense, enhancing neutrophil killing of Staphylococcus aureus. Cell Host Microbe 10: 158-164.

23. Liu JZ, Jellbauer S, Poe A, Ton V, Pesciaroli M, et al. (2012) Zinc sequestration by the neutrophil protein calprotectin enhances Salmonella growth in the inflamed gut. Cell Host Microbe 11: 227-239.

24. Urban CF, Ermert D, Schmid M, Abu-Abed U, Goosmann C, et al. (2009) Neutrophil extracellular traps contain calprotectin, a cytosolic protein complex involved in host defense against Candida albicans. PLoS Path 5: e1000639.

25. Actis LA, Tolmasky ME, Crosa LM, Crosa JH (1993) Effect of iron-limiting conditions on growth of clinical isolates of Acinetobacter baumannii. J Clin Microbiol 31: 2812-2815.

26. Dorsey CW, Beglin MS, Actis LA (2003) Detection and analysis of iron uptake components expressed by Acinetobacter baumannii clinical isolates. J Clin Microbiol 41: 4188-4193.
27. Dorsey CW, Tolmasky ME, Crosa JH, Actis LA (2003) Genetic organization of an Acinetobacter baumannii chromosomal region harbouring genes related to siderophore biosynthesis and transport. Microbiology 149: 1227-1238.

28. Dorsey CW, Tomaras AP, Connerly PL, Tolmasky ME, Crosa JH, et al. (2004) The siderophore-mediated iron acquisition systems of Acinetobacter baumannii ATCC 19606 and Vibrio anguillarum 775 are structurally and functionally related. Microbiology 150: 3657-3667.

29. Echenique JR, Arienti H, Tolmasky ME, Read RR, Staneloni RJ, et al. (1992) Characterization of a high-affinity iron transport system in Acinetobacter baumannii. J Bacteriol 174: 7670-7679.

30. Zimbler DL, Penwell WF, Gaddy JA, Menke SM, Tomaras AP, et al. (2009) Iron acquisition functions expressed by the human pathogen Acinetobacter baumannii. Biometals 22: 23-32.

31. Hsu K, Champaiboon C, Guenther BD, Sorenson BS, Khammanivong A, et al. (2009) Anti-infective protective properties of S100 calgranulins. Antiinflamm Antiallergy Agents Med Chem 8: 290-305

32. McCormick A, Heesemann L, Wagener J, Marcos V, Hartl D, et al. (2010) NETs formed by human neutrophils inhibit growth of the pathogenic mold Aspergillus fumigatus. Microb Infect 12: 928-936.

33. Terrin G, Passariello A, Manguso F, Salvia G, Rapacciuolo L, et al. (2011) Serum calprotectin: an antimicrobial peptide as a new marker for the diagnosis of sepsis in very low birth weight newborns. Clin Dev Immunol 2011: 291085.

34. Brandtzaeg P, Gabrielsen TO, Dale I, Müller F, Steinbakk M, et al. (1995) The leucocyte protein L1 (calprotectin): a putative nonspecific defence factor at epithelial surfaces. Adv Exp Med Biol 371A: 201-206.

35. Oiu H, KuoLee R, Harris G, Chen W (2009) Role of NADPH phagocyte oxidase in host defense against acute respiratory Acinetobacter baumannii infection in mice. Infect Immun 77: 1015-1021

36. van Faassen H, KuoLee R, Harris G, Zhao X, Conlan JW, et al. (2007) Neutrophils play an important role in host resistance to respiratory infection with Acinetobacter baumannii in mice. Infect Immun 75: 5597-5608.

37. Attia AS, Schroeder KA, Seeley EH, Wilson KJ, Hammer ND, et al. (2012) Monitoring the inflammatory response to infection through the integration of MALDI IMS and MRI. Cell Host Microbe 11: 664-673.

38. Manitz M-P, Horst B, Seeliger S, Strey A, Skryabin BV, et al. (2003) Loss of S100A9 (MRP14) results in reduced interleukin-8-induced CD11b surface expression, a polarized microfilament system, and diminished responsiveness to chemoattractants in vitro. Mol Cell Biol 23: 1034-1043.

39. Rahman SMJ, Gonzalez AL, Li M, Seeley EH, Zimmerman LJ, et al. (2011) Lung cancer diagnosis from proteomic analysis of preinvasive lesions. Cancer Res 71: 3009-3017.

40. Ammendola S, Pasquali P, Pistoia C, Petrucci P, Petrarca P, et al. (2007) Highaffinity Zn2+ uptake system ZnuABC is required for bacterial zinc homeostasis in intracellular environments and contributes to the virulence of Salmonella enterica. Infect Immun 75: 5867-5876.

41. Campoy S, Jara M, Busquets N, Pérez De Rozas AM, Badiola I, et al. (2002) Role of the high-affinity zinc uptake znuABC system in Salmonella enterica serovar Typhimurium virulence. Infect Immun 70: 4721-4725.

42. Davis LM, Kakuda T, DiRita VJ (2009) A Campylobacter jejuni znuA orthologue is essential for growth in low-zinc environments and chick colonization. J Bacteriol 191: $1631-1640$

43. Desrosiers DC, Bearden SW, Mier I, Abney J, Paulley JT, et al. (2010) Znu is the predominant zinc importer in Yersinia pestis during in vitro growth but is not essential for virulence. Infect Immun 78: 5163-5177.

44. Shin J-H, Jung HJ, An YJ, Cho Y-B, Cha S-S, et al. (2011) Graded expression of zinc-responsive genes through two regulatory zinc-binding sites in Zur. Proc Natl Acad Sci U S A 108: 5045-5050.

45. Gaballa A, Helmann JD (1998) Identification of a zinc-specific metalloregulatory protein, Zur, controlling zinc transport operons in Bacillus subtilis. J Bacteriol 180: 5815-5821.

46. Huang D-L, Tang D-J, Liao Q Li H-C, Chen Q et al. (2008) The Zur of Xanthomonas campestris functions as a repressor and an activator of putative zinc homeostasis genes via recognizing two distinct sequences within its target promoters. Nucleic Acids Res 36: 4295-4309.

47. Li Y, Qiu Y, Gao H, Guo Z, Han Y, et al. (2009) Characterization of Zurdependent genes and direct Zur targets in Yersinia pestis. BMC Microbiol 9: 128.

48. Panina EM, Mironov AA, Gelfand MS (2003) Comparative genomics of bacterial zinc regulons: enhanced ion transport, pathogenesis, and rearrangement of ribosomal proteins. Proc Natl Acad Sci U S A 100: 9912-9917.

49. Kallifidas D, Pascoe B, Owen GA, Strain-Damerell CM, Hong H-J, et al. (2010) The zinc-responsive regulator Zur controls expression of the coelibactin gene cluster in Streptomyces coelicolor. J Bacteriol 192: 608-611.

50. Maciag A, Dainese E, Rodriguez GM, Milano A, Provvedi R, et al. (2007) Global analysis of the Mycobacterium tuberculosis Zur (FurB) regulon. J Bacteriol 189: 730-740.

51. Stork M, Bos MP, Jongerius I, de Kok N, Schilders I, et al. (2010) An outer membrane receptor of Neisseria meningitidis involved in zinc acquisition with vaccine potential. PLoS Path 6: e1000969.

52. Kumar P, Sannigrahi S, Tzeng Y-L (2012) The Neisseria meningitidis ZnuD zinc receptor contributes to interactions with epithelial cells and supports heme utilization when expressed in Escherichia coli. Infect Immun 80: 657-667. 
53. Eijkelkamp B, Hassan K, Paulsen I, Brown M (2011) Investigation of the human pathogen Acinetobacter baumannii under iron limiting. BMC Genomics 12: 126.

54. Esterly JS, Griffith M, Oi G, Malczynski M, Postelnick MJ, et al. (2011) Impact of carbapenem resistance and receipt of active antimicrobial therapy on clinical outcomes of Acinetobacter baumannii bloodstream infections. Antimicrob Agents Chemother 55: 4844-4849.

55. Queenan AM, Pillar CM, Deane J, Sahm DF, Lynch AS, et al. (2012) Multidrug resistance among Acinetobacter spp. in the USA and activity profile of key agents: results from CAPITAL Surveillance 2010. Diagn Microbiol Infect Dis 73: 267270 .

56. Sowmiya M, Umashankar V, Muthukumaran S, Madhavan H, Malathi J (2012) Studies on New Delhi Metallo-Beta-Lactamse-1 producing Acinetobacter baumannii isolated from donor swab in a tertiary eye care centre, India and structural analysis of its antibiotic binding interactions. Bioinformation 8: 445-452.

57. Nordmann P, Poirel L, Walsh TR, Livermore DM (2011) The emerging NDM carbapenemases. Trends Microbiol 19: 588-595.
58. Adams MD, Goglin K, Molyneaux N, Hujer KM, Lavender H, et al. (2008) Comparative genome sequence analysis of multidrug-resistant Acinetobacter baumannii. J Bacteriol 190: 8053-8064.

59. Kehl-Fie TE, Skaar EP (2010) Nutritional immunity beyond iron: a role for manganese and zinc. Curr Opin Chem Biol 14: 218-224.

60. Jacobs AC, Hood I, Boyd KL, Olson PD, Morrison J, et al. (2010) Inactivation of Phospholipase D diminishes Acinetobacter baumannii pathogenesis. Infect Immun 78: 1952-1962.

61. Aranda J, Poza M, Pardo B, Rumbo S, Rumbo C, et al. (2012) A rapid and simple method for constructing stable mutants of Acinetobacter. BMC Microbiol 10: 279 .

62. Bailey TL, Williams N, Misleh C, Li WW (2006) MEME: discovering and analyzing DNA and protein sequence motifs. Nucleic Acids Res 34: W369 W373.

63. Crooks GE, Hon G, Chandonia JM, Brenner SE (2004) WebLogo: a sequence logo generator. Genome Res 14: 1188-1190. 